\title{
Advanced exergy analysis of distillation tower and simulation and optimization by hysys
}

\author{
Mohsen Darabi $^{1 *}$, Hamid Mohammadiun ${ }^{2}$, Mohammad Mohammadiun ${ }^{2}$ \\ ${ }^{I}$ Young Researchers and Elite Club, shahrood Branch, Islamic Azad University shahrood, Iran \\ ${ }^{2}$ Assistant Professor, Department of Mechanical Engineering,Shahrood Branch, Islamic Azad University, Shahrood,Iran \\ *Corresponding author E-mail: mohsendarabi313@yahoo.com
}

Copyright $(92015$ Mohsen Darabi et al. This is an open access article distributed under the Creative Commons Attribution License, which permits unrestricted use, distribution, and reproduction in any medium, provided the original work is properly cited.

\begin{abstract}
Exergy rate profiles, exergetic efficiency and irreversibility were used to examine the driving forces in multicomponent distillation system with the view to identifying feasible and efficient operating parameters. The mixture comprised of 5\% propane, $15 \%$ iso butane, $25 \% \mathrm{n}$-butane, $20 \%$ iso pentane and $35 \% \mathrm{n}$-pentane. Operating variables were feed temperature $(-30 \mathrm{oC}$ and $-80 \mathrm{oC})$, pressure $(800 \mathrm{KPa}$ and $1200 \mathrm{KPa})$, and reflux-ratio (2 and 6). Sensitivity analysis was carried out to examine the effect of varying operating parameters on the systems. Stage-by-stage system exergy analysis was estimated. Column profiles of a base case $-30 \mathrm{oC},-80 \mathrm{oC},-30 \mathrm{oC}$-reflus ratio $6,80 \mathrm{oC}-80 \mathrm{oC}$ reflux ratio 6 and base case reflux ratio 6 did not cross thus are thermodynamically feasible. Base case $-30 \mathrm{oC}$-reflux ratio $2,-80 \mathrm{oC}$-reflux ratio 2 , and base case-reflux ratio 2 were crossed and constricted and are infeasible. Base case results gave efficiency of $81.7 \%$ at depropanizer and $65.2 \%$ at debutanizer. Base cases sensitivity results with $-30 \mathrm{oC},-80 \mathrm{oC}$ and reflux ratio 6 , efficiency range $57.40-70 \%$ and $65.20 \%-54.90 \%$ for depropanizer and debutanizer respectively. Spitted cases gave $81.7 \%$ and $62.20 \%$ with more scatter profiles. Splitted feed base case $-30 \mathrm{oC}$ design gave the lowest overall system exergy loss rate of $1.12 \mathrm{E}+6$ and efficiency of $95.70 \%$.
\end{abstract}

Keywords: Hysys; Exergy Analysis; Simulation and Optimization; Multicomponent.

\section{Introduction}

Distillation is the most-used separation operation in chemical and petrochemical industries, and its ever growing application is accompanied by a large increase in consumption of energy [8]. It is known that distillation is used for the separation of about $95 \%$ of all fluid separations in the chemical, industry, and that around 3\% of the total energy consumption throughout the world is used in distillation units [7]. According to some recent estimates, about $40 \%$ of energy involved in refinery and other continuous chemical processes are consumed in distillation [21]. For this reason, the energy-efficient design and operation of distillation processes is an important issue discussed in various literatures [15], [9]. These analyses have focused only on energy and ignored the quality of energy. The energy demand of a distillation system is an increasingly important process performance factor, due to the increasing pressure to save energy.

The determination of the minimum energy requirements of different distillation systems can offer an early assessment tool for comparing structural alternatives and efficiency. The thermal energy added at the reboiler is used to evaporate a liquid mixture and is lost when liquefying the vapour flow at the condenser to obtain a reflux liquid flow. However, the thermal energy recovered at the condenser cannot be used to heat other flows in the same distillation column since the temperature of the cooling medium is usually much lower than that of the flows inside the column. Motivated by the large demand of energy in distillation processes, researchers have developed new arrangements that can amass savings in both energy and capital costs.

The high consumption of energy in distillation systems has led to the search of more energy-efficient schemes for the separation of fluid mixtures in chemical processes. One of such options is the use of interconnected distillation systems, 
commonly referred to as thermally coupled distillation sequences (TCDS). Thermally coupled arrangements have been developed to a greater extent for the separation of three-component mixtures; thermally coupled systems with a side rectifier or with a side stripper, and the fully integrated distillation column (or Petlyuk system) have been shown to provide important energy savings with respect to use of conventional distillation sequences [1], [10], [11], [12], [13],[26]. The energy savings seem to be more significant for the separation of mixtures with low contents of the intermediate component of the ternary mixture. A few attempts have been made to extend the concepts of integrated columns to four or five component mixtures, either based on conceptual arrangements or on shortcut methods [4], [24], [3] have shown a more formal design strategy for two types of thermally coupled systems for four-component mixtures, one with a side rectifier and a side stripper (TCDS-SR/SS) and the other one based on an extension of the Petlyuk system (TCDS-PR). Their analysis showed how a design for each integrated sequence can be obtained from the tray structure of a conventional distillation sequence, and how such a design can be optimized for minimum energy consumption through a search procedure over the interconnecting streams.

Tray distillation is most commonly modelled by assuming that equilibrium is established between the vapour and the liquid at the outlets of each tray in the column. However, in reality, equilibrium is not reached. The first attempt to account for the irreversible nature of the process was to introduce tray efficiencies. The Murphree efficiency measures to which degree equilibrium is reached [16]. The Murphree efficiency has been used to describe distillation with some success for binary mixtures at the steady state. The method brakes down for multi-component systems or for dynamic behaviour. Moreover, the Murphree efficiency provides no physical explanation for why equilibrium was not reached. Besides stand-alone optimization, methods that provide a systematic procedure for a better heat integration of columns with the background process have also been sought for. Exergy Analysis has been used successfully to assess the thermodynamic efficiency of distillation columns [30], [20]. Exergy is a thermodynamic property that measure the quality of energy contained in a substance and of its departure in temperature, pressure and composition from the environmental conditions. Consequently, it allows consideration in an integral way energetic, economic and ecological aspect in analysing industrial processes [22].

Thus going a step further, to evaluate the quality of energy lost via exergy analysis is an efficient technique for reducing inefficiencies. A careful evaluation of process and plant design using Exergy analysis enables the identification and quantification of the sources of inefficiencies or process irreversibility-related losses. Exergy analysis includes conservation of mass and energy balance together with the second law of thermodynamics. [2] Published a thermodynamic analysis of crude oil distillation systems, which includes aspects like energy and exergy analysis, performance evaluation and system optimization. [29] Have shown that large savings could be obtained because of reduction of high-quality energy. The use of irreversible thermodynamic principles in the field of distillation is still under development [23]. Le Goff and Hornut [17] presented results on exergy analysis and exergoeconomic analysis of industrial processes. However, traditional exergy analysis has focused on the overall thermodynamic efficiency of separation and the relation of spent work (utility consumption) to the ideal work required for the separation. Very little information about how to proceed to optimize the column is converged to the engineer. More recent work in the application of exergy analysis to the optimization of distillation columns considers the column as a reversible process [6]. The resulting temperature-enthalpy profile allows the engineer to identify useful modifications to increase the thermal efficiency of the column, and allow a better heat integration of the process. Beneficial changes in operating conditions and layout, like feed condition and the use of using side-condenser or/and side-reboiler can be identified, and its suitability to be heat integrated with other processes. However, the assumption of reversibility presents some limitations for the application of this methodology to multicomponent systems [27]. Several attempts had been made by various researchers to introduce diagrammatic methods that could aid to the design and retrofit of energy efficient distillation processes [25], [19], [28], [6], and [5]. Much consideration has not been given to multicomponent distillation systems.

The aim of the research is to develop a method of using exergy analysis to generate exergetic driving forces in columns of a multicomponent distillation system. This work deals with a study of separation into components mixture comprising five components $-5 \%$ propane, $15 \%$ iso-butane, $25 \%$ n-butane, $20 \%$ isopentane and $35 \%$ n-pentane and presents a stage exergy rate diagrams (profiles) in determining the feasibility and efficiency of multicomponent distillation system.

\section{Methodology}

\subsection{Model simulation and data extraction}

The distillation separation of the mixture into pure components was carried out using Hyprotech System Simulator (HYSYS vs. 3.2). A number of property package are available for use in the HYSYS environment, each of which could be used individually. For this study, Peng Robinson was selected for the property package simulation, and a combination of the property packages filter were used; that is Equation of State, Activity models, Chao Seader models, vapour pressure models and miscellaneous types. This was done in order to reduce complications that may arise in the course of simulation. To proceed with the thermodynamic analysis, the following data were extracted from the simulation, for each feed, product and internal liquid and vapour streams on a tray-by-tray basis; flows rates, 
temperature, pressure, enthalpy and entropy. Secondly stream compositions, temperature, pressure, enthalpy and entropy at reference temperature and pressure (environmental condition).

Four columns were selected in series with the bottom product of one serving as the inlet feed of the next. The columns are named Depropanizer, Debutanizer, Butane splitter and Pentane splitter sequentially. The specifications of the first column of the base case include feed temperature of $-50 \mathrm{oC}$, feed pressure of $1000 \mathrm{KPa}$, and reflux ratio of 4 . The model was for a total condenser. The simulation was carried out for these initial specifications and HYSYS was used to generate the temperature, pressure, specific enthalpy, and specific entropy and flow rates for every stream in and out of each column; the tray by tray temperature, pressure and specific enthalpy were obtained by HYSYS simulation results. The specific enthalpy and entropy for the tray by tray vapor and liquid phase at reference (environmental conditions) temperature of $293 \mathrm{~K}$ and reference pressure of $101.3 \mathrm{KPa}$ state were obtained from the HYSIS mixer model. The negative values obtained from the change in enthalpy, and entropy was shifted by addition of certain positive value a little above the lowest negative enthalpy or/and entropy values.

\subsection{Exergy calculation}

The exergy balance for open systems at steady state used was given by Jean-Francois et al (2008) as;

$$
E x_{h p}=\left(H-H_{o}\right)-T_{0}\left(s-s_{o}\right)
$$

$\mathrm{I}=\mathrm{V} 2 * \mathrm{ExV}+\mathrm{ExQc}-(\mathrm{L} 1+\mathrm{D}) * \mathrm{ExL}$

Tray by tray irreversibility was obtained by expressing given by Douani et al., 2007

$\mathrm{I}=\mathrm{Lj}-1 * \operatorname{ExL}+\mathrm{Vj}+1 * \operatorname{ExV} \mathrm{Fj} * \operatorname{ExF}+\operatorname{ExQj}-(\mathrm{Lj}+\mathrm{M} \mathrm{j}) * \operatorname{ExL}-(\mathrm{Vj}+\mathrm{U} \mathrm{j}) * \mathrm{ExV}$

The first law (energy) and second law (exergy) efficiency are expressed by the equations

$\Psi=\frac{\sum E x_{0}}{\sum E x_{i}}$

$\eta=\frac{\sum E}{\sum E}$

The exergetic efficiency for a real column is written:

$\eta_{e x}=\frac{L N * E x L+D 1^{*} E X-F * E X}{E X Q R-E X Q C}$

Application of equation (3.7), (3.8), (3.9), and (3.10) to the multicomponent distillation process considered in this research work gave the exergy efficiency and irreversibility equations:

$\mathrm{I} N=-\mathrm{VN} * \mathrm{ExN}+\mathrm{ExQr}-\mathrm{LN} * \mathrm{ExN}+\mathrm{LN}-1 * \mathrm{ExN}-1$

$I=\left[\right.$ EXfeed $\left.+\left(1-\frac{T 0}{T \text { erboiler }}\right) Q_{\text {erboiler }}\right]-\left[\right.$ EXDISTILLATE + EXBOTTOM $+\left(1-\frac{T 0}{\text { TCONDENSER }}\right)$ QCONDENSER $]$

Where

Tcondenser=Tdisillate - Avg temperature difference between the condenser and the stream

Exergy efficency $=$

useful exergy variation

$\overline{\text { consumed energy tranformation }}$

Treboiler $=$ T reboiler + Avg temperature difference between the reboiler and the stream

\subsection{Stage exergy rate diagrams}

At every stage of the distillation column, the liquid and the vapor enthalpy and exergy rate values were calculated. The rate diagrams were then generated from a plot of exergy rate of the tray by tray liquid and vapor phases versus tray 
number. Columns exergetic driving forces and was determined from the exergy rate profiles. Exergetic efficiency and irreversibility was also obtained and was used to with the exergetic driving forces obtained to determine feasible and efficient system. Sensitivity analysis was carried out to identify the effect of variation in the operating parameters (both process and design variables) on the systems. The operating variables considered are feed temperature and pressure, and reflux-ratio. The temperature variation was for $-30 \mathrm{oC}$ and $-80 \mathrm{oC}$. Pressure variation was $800 \mathrm{KPa}$ and $1200 \mathrm{KPa}$ and reflux ratio variation considered was 2 and 6 and for flow rate variation, splitted feed was considered. The sensitivity results were used to identify various feasible operating parameters for the multicomponent distillation system studied.

\section{Results and discussions}

\subsection{Simulation sequence for separation into pure components}

In the first part, converged simulation results show that the model presented gave in perfect adequacy with the experimental data in that the sequence achieved $100 \%$ pure separation of components. Fig. 1 gives the process flow model sequence for single feed system, and Fig. 2 gives the process flow model sequence for splitted feed system. These systems consist of four columns - two distillation columns (Depropanizer and debutanizer) and two-component splitters (butane and pentane component splitters). The stages are numbered starting from the condenser, and the simulation is for total condenser. The Depropanizer consist of 55 and feed fed on tray 19 while debutanizer consist of 62 stages/trays and feed was fed on tray 31. The profiles of component composition (mole fraction) versus tray number for the pure separation processes obtained by the simulation sequences are given in Fig. 3 and Fig. 4 . Fig. 3 revealed that pure propane was obtained from the top of the column as distillate leaving the other components as liquid to the bottom of the column. The results also showed that the composition of propane was vaporized at the feed inlet position located on tray 19. Fig. 4 showed the $100 \%$ pure iso-butane, and n-butane was vaporized on the feed location and was separated to the top of the column as distillate leaving iso-pentane and n-pentane as liquid to the bottom of the column. Pure iso-butane and n-butane were obtained from the butane splitter component. Similarly, pure iso-pentane and npentane were separated by the pentane component splitter.

\subsection{Exergy rate (diagram) profile}

The exergy rate diagram gives a pictorial representation of the happening within the column as regards the exergy profile. Specific enthalpy diagram was used by [19] to show the heat and mass transfer effect in the distillation of a binary mixture but the profiles, here are for the case of total enthalpy, which is all encompassing. The liquid and vapour profiles for each stage of the column reveals the driving force within the column and gives insight into the feasibility of a given operation for some set of operating conditions. The exergy rate diagram has the added advantage of determining the feasibility of not only binary columns but multicomponent columns as well. This research gives credence to this. For feasible design, the profiles are not expected to cross nor be constricted. This is because their crossing will amount to reversal of driving force within the column and hence make such design an infeasible one. Constriction situation is a case where the liquid and vapour lines do not cross but give extremely close profile. Constriction cases though feasible are undesired because such condition renders the design inefficient in terms of energy usage.

Fig. 5 and 6 shows the exergy rate diagrams for the columns of the base case design. The Depropanizer exergy profile (Fig. 3.5) did not cross at any points and so the specifications for this column are realistic and feasible. The exergy profile for debutanizer shown in Fig. 6 did not cross hence operating the debutanizer at the specified conditions are feasible. The base case design with splitted feed exergy profiles neither cross nor constricted as shown in Fig. $6-7$. Here the liquid and vapour profiles are well spaced and scattered. Therefore, operating the distillation system at the specified conditions with splitted feed is thermodynamically feasible. Exergy profiles for sensitivity analysis were presented in Fig. 9 - 27. Profiles base case -30oC, 80oC, 30oC-Reflus -80oC, -30oC-Reflus ratio 6, -80oC-Reflux ratio 6 and base case-Reflux ratio 6 were not crossed. Profiles of base case -30oC-Reflux ratio 2, -80oC-Reflux ratio 2, and base case-Reflux ratio 2 gave crossing in their depropanizer. The columns and systems exergetic efficiency and their corresponding irreversibility's (exergy loss rate) systems are shown in Table 3.1 and Table 3.2. Base cases results gave an exergy efficiency of $81.7 \%$ at depropanizer and $65.2 \%$ at debutanizer. Base cases sensitivity results with $-30 \mathrm{oC}, 80 \mathrm{oC}$ $-80 \circ \mathrm{C}$ and reflux ratio 6, efficiency range $57.40-70 \%$ and $65.20 \%-54.90 \%$ for depropanizer and debutanizer respectively. Spitted feed base case gave same exergy efficiency range of $81.7 \%$ and $62.20 \%$ when compared respectively with depropanizer and debutanizer of base cases. $800 \mathrm{KPa}$ case gave $82.1 \%$ and $62.5 \%$ at depropanizer and debutanizer respectively. $1200 \mathrm{KPa}$ case gave much lower exergy efficiency $0.66 \%$ and $0.65 \%$ at depropanizer and debutanizer respectively, which do not compare well with the efficiencies given by the base cases, splitted feed cases and $800 \mathrm{KPa}$ cases. This shows that operating this multicomponent distillation system at feed pressure of $1200 \mathrm{KPa}$ will be grossly inefficient and unrealistic despite the feasible exergy rate diagram. This confirms the need not to supplement the second law efficient calculation with the exergy rate diagram to determine the actual feasible operations and design. By overall system exergy efficiency, splitted base Case $(-30 \mathrm{oC}-1000 \mathrm{KPa})$ gave better efficiency of $97.99 \%$ over the other base cases $-30 \mathrm{oC}$ of $95.70 \%$. Exergy loss rate (irreversibility) indicated that base Cases $(-30 \mathrm{oC}-1000 \mathrm{KPa})$ gave 
lower overall value of 1.51E+06. Multiple (splitted) feed for splitted base Case (-30oC-1000KPa gave an enhance exergetic efficiencies of $97.99 \%$ and much lower exergy loss (irreversibilities) of $1.12 \mathrm{E}+06$.

\section{Conclusion and recommendtions}

The use of exergy analysis in improving the operation of multicomponent distillation from the dimension of exergy rate diagram has been emphasised. There is a need to optimize the examined feasible operating condition ranges and also determine columns exergy loss distribution profiles in order to determine the optimum condition of operating this multicomponent distillation system. There are great potentials of applying exergy rate diagrams to other chemical processes.

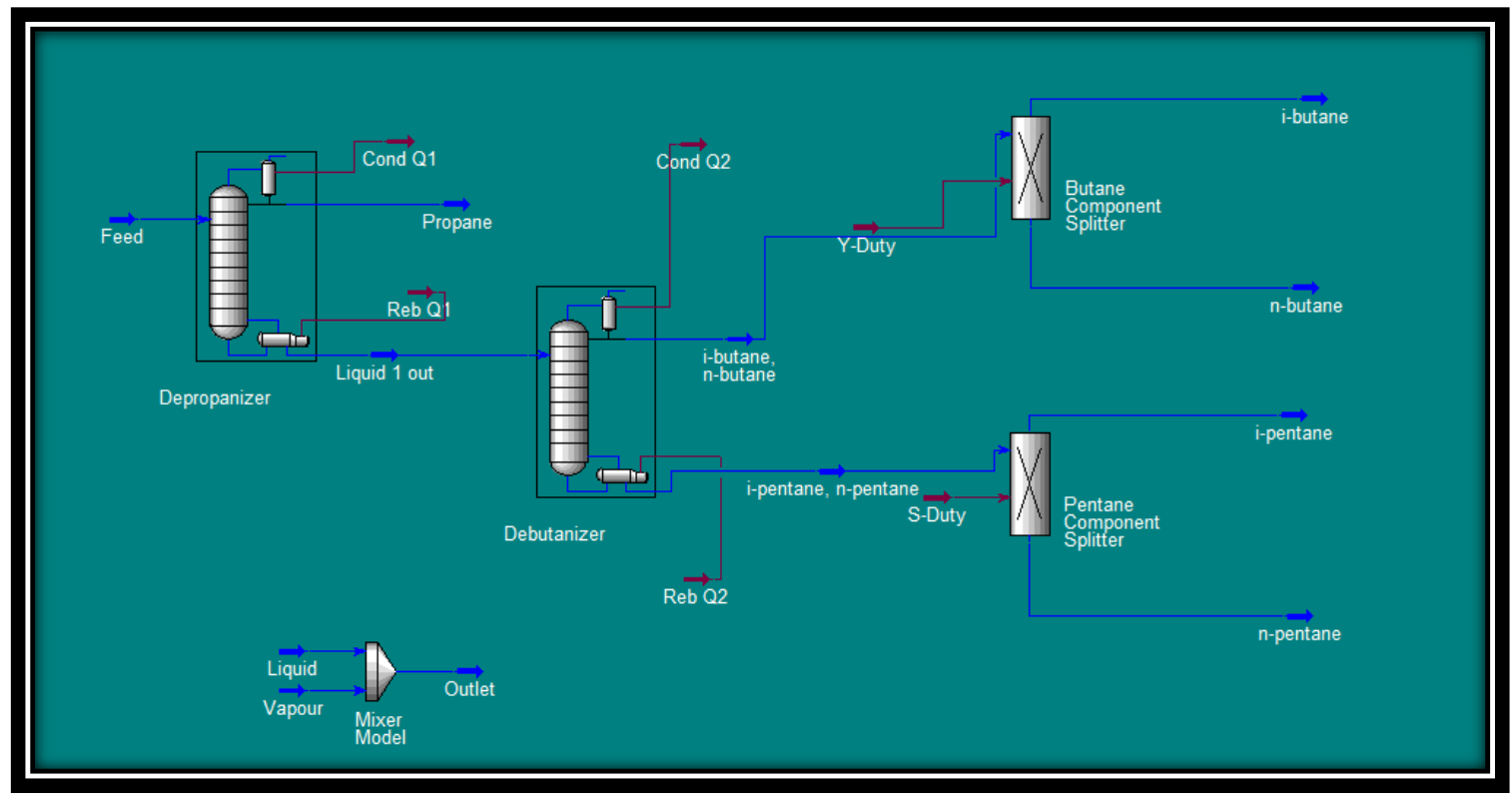

Fig. 1: Process Flow Diagram for Single Feed Multicomponent System.

Table 1: Comparison of Columns and Systems Exergetic Efficiency for Feasible Sensitivity Design Cases, Splitted

\begin{tabular}{llll}
\hline Design Process Conditions & Irreversibility (KJ/hr) & & \\
& Depropanizer & Debutanizer & System \\
\hline Base Case (-50oC, 1000Kpa, RR4) & $1.05 \mathrm{E}+7$ & $2.54 \mathrm{E}+7$ & $3.58 \mathrm{E}+7$ \\
Base Case (-30oC, 1000Kpa, RR4) & $7.78 \mathrm{E}+6$ & $2.49 \mathrm{E}+7$ & $1.51 \mathrm{E}+6$ \\
Base Case (-80oC, 1000Kpa, RR4) & $1.23 \mathrm{E}+7$ & $2.54 \mathrm{E}+7$ & $3.76 \mathrm{E}+7$ \\
Base Case (-30oC, 1000Kpa, RR6) & $9.08 \mathrm{E}+6$ & $3.33 \mathrm{E}+7$ & $4.41 \mathrm{E}+7$ \\
Base Case (-80oC, 1000Kpa, RR6) & $1.36 \mathrm{E}+7$ & $3.33 \mathrm{E}+7$ & $4.38 \mathrm{E}+7$ \\
Base Case (-50oC, 1000Kpa, RR6) & $1.07 \mathrm{E}+7$ & $3.33 \mathrm{E}+7$ & $1.58 \mathrm{E}+7$ \\
1200KPa (-50oC, RR4) Case & $9.10 \mathrm{E}+6$ & $2.54 \mathrm{E}+7$ & $6.17 \mathrm{E}+6$ \\
800KPa (-50oC, RR4) Case & $1.05 \mathrm{E}+7$ & $2.54 \mathrm{E}+7$ & $3.59 \mathrm{E}+7$ \\
Splitted Feed Case (-50oC, 1000Kpa, RR4) & $1.05 \mathrm{E}+7$ & $2.54 \mathrm{E}+7$ & $3.58 \mathrm{E}+7$ \\
Splitted Feed Case (-30oC, 1000Kpa, RR4) & $7.79 \mathrm{E}+6$ & $2.16 \mathrm{E}+7$ & $1.12 \mathrm{e}+6$ \\
\hline
\end{tabular}




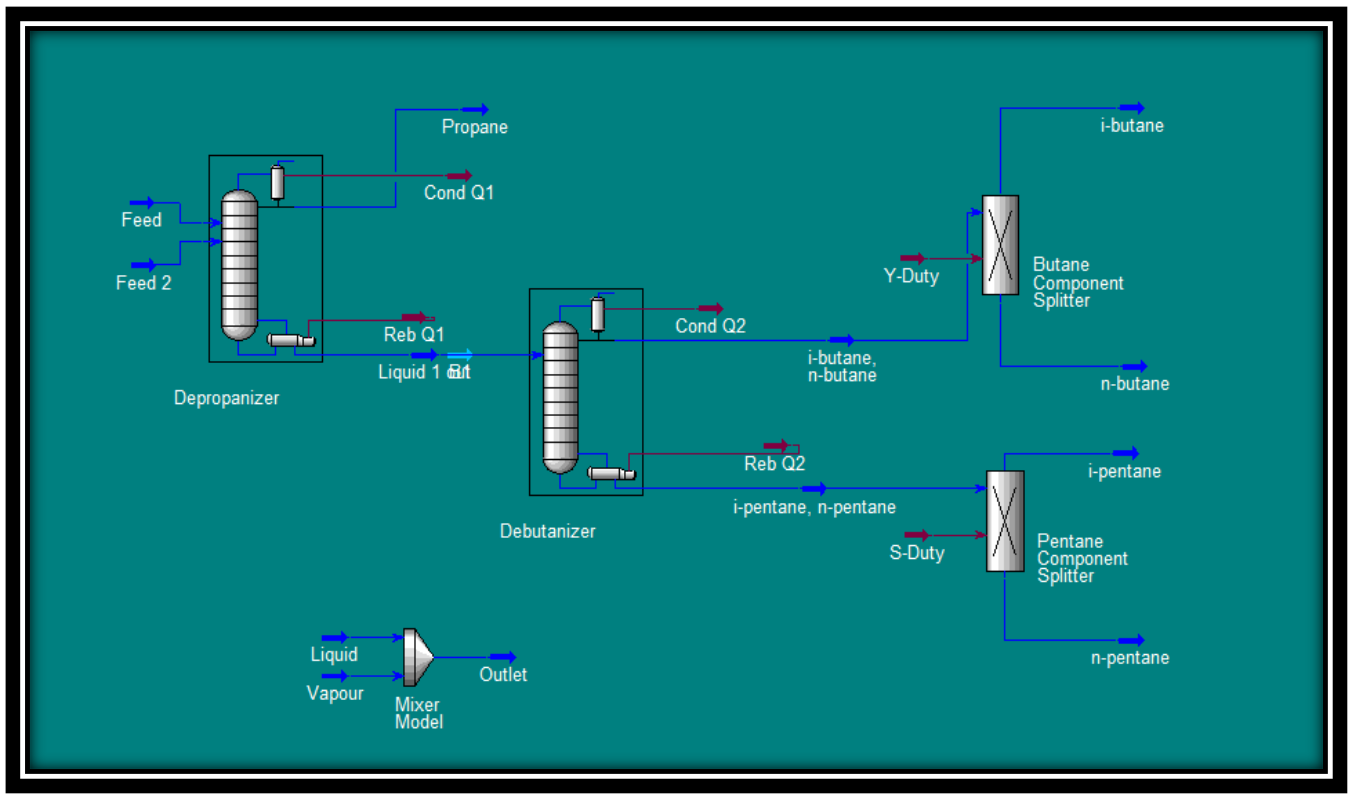

Fig 2: Process Flow Diagram for Splitted Feed Multicomponent

Table 3.2: Comparison of Columns and Systems Irreversibility (Exergy Loss) for Feasible Design Cases

\begin{tabular}{lllll}
\hline \multirow{2}{*}{ Design Case } & \multirow{2}{*}{ Design Process Conditions } & \multicolumn{2}{c}{ Exergy Efficiency (\%) } \\
& & Depropanizer & Debutanizer & System \\
\hline 1 & Base Case (-50oC, 1000Kpa, RR4) & 81.70 & 65.20 & 58.72 \\
2 & Base Case (-30oC, 1000Kpa, RR4) & 70.00 & 54.90 & 95.70 \\
3 & Base Case (-80oC, 1000Kpa, RR4) & 79.60 & 65.20 & 58.17 \\
4 & Base Case (-30oC, 1000Kpa, RR6) & 66.80 & 61.30 & 79.98 \\
5 & Base Case (-80oC, 1000Kpa, RR6) & 57.40 & 61.30 & 75.22 \\
6 & Base Case (-50oC, 1000Kpa, RR6) & 63.00 & 61.30 & 78.16 \\
7 & 1200KPa (-50oC, RR4) Case & 0.66 & 0.65 & 89.18 \\
8 & 800KPa (-50oC, RR4) Case & 82.10 & 65.20 & 59.50 \\
9 & Splitted Feed Case (-50oC, 1000Kpa, RR4) & 81.70 & 65.20 & 58.72 \\
10 & Splitted Feed Case (-30oC, 1000Kpa, RR4) & 81.70 & 65.20 & 97.99 \\
\hline
\end{tabular}

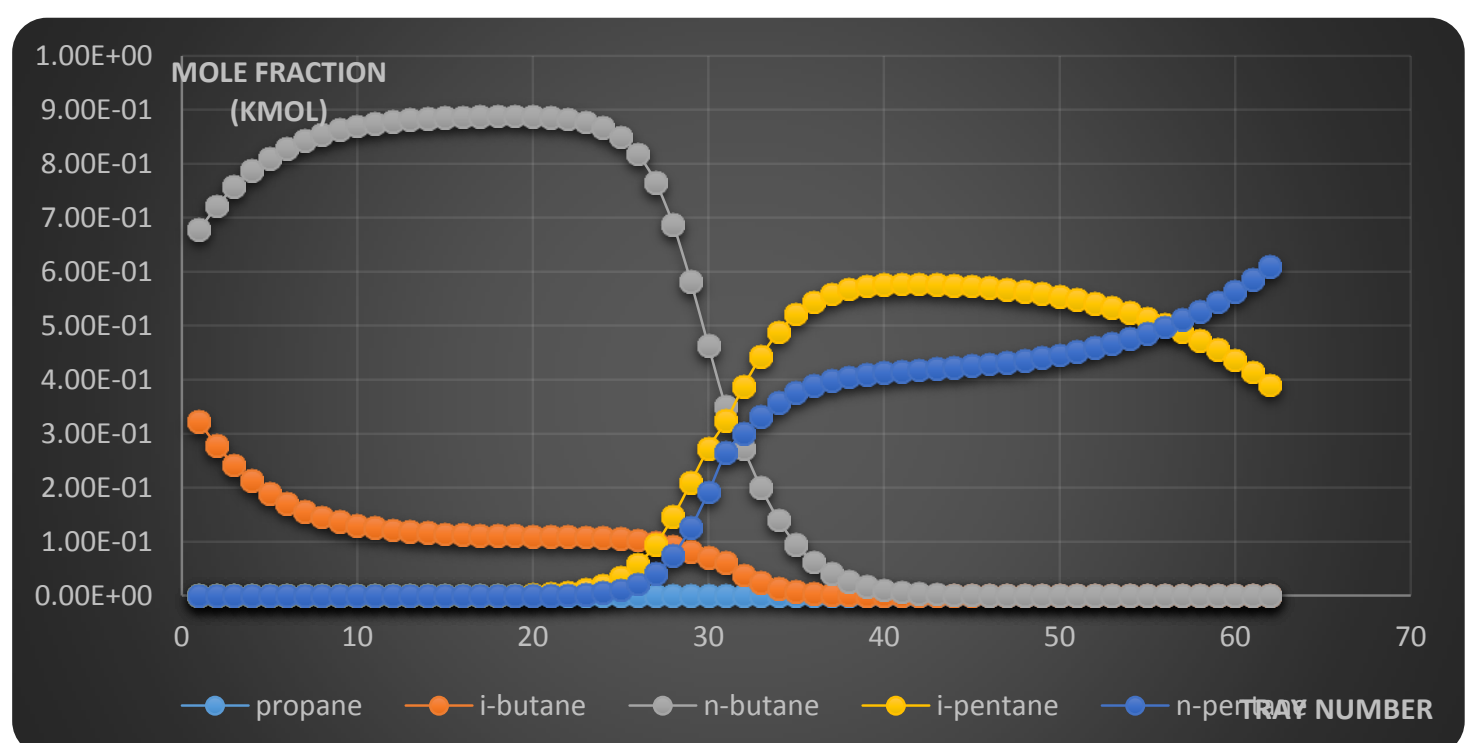

Fig. 3: Molar Composition of Depropanizer of the Base Case 


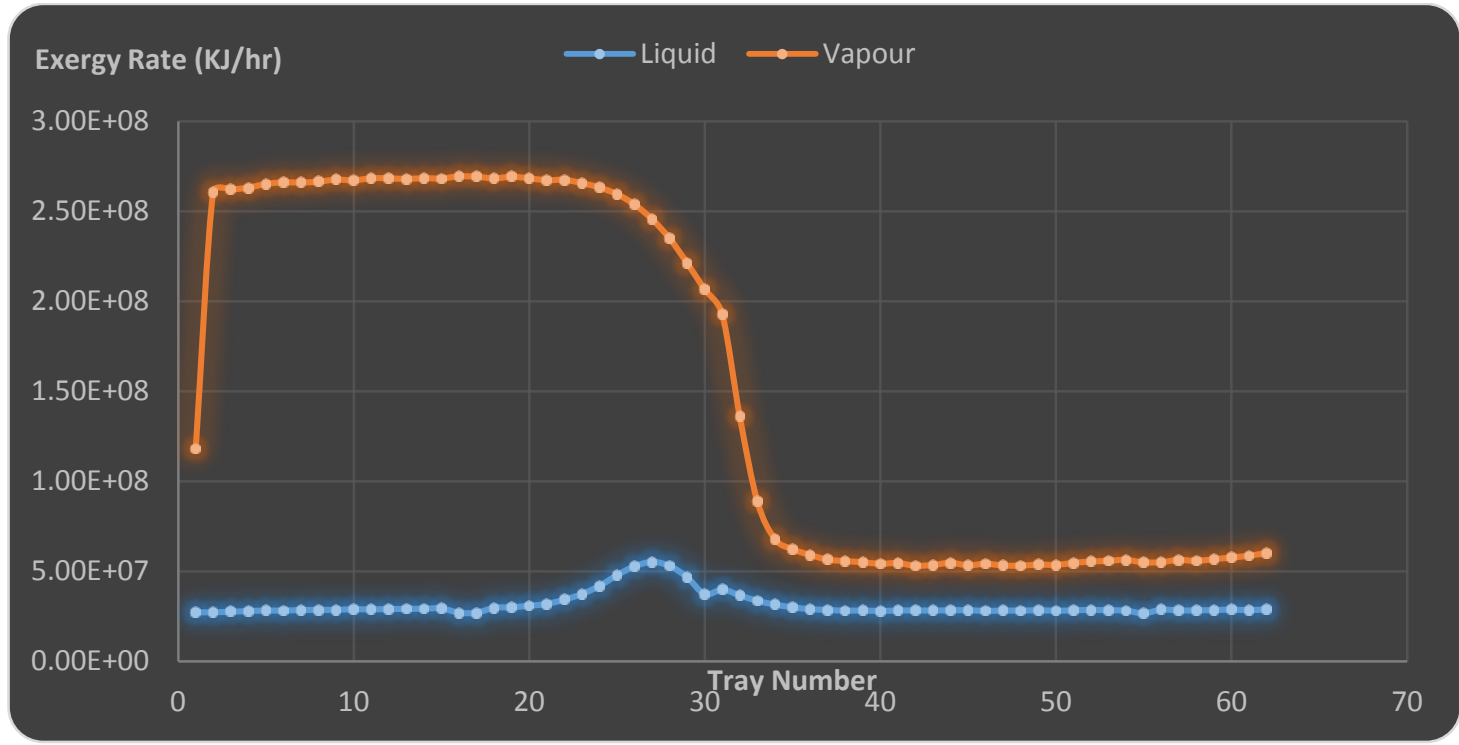

Fig. 4: Profile of Exergy Rate versus Tray Numberthe for Debutanizer of the Base Case

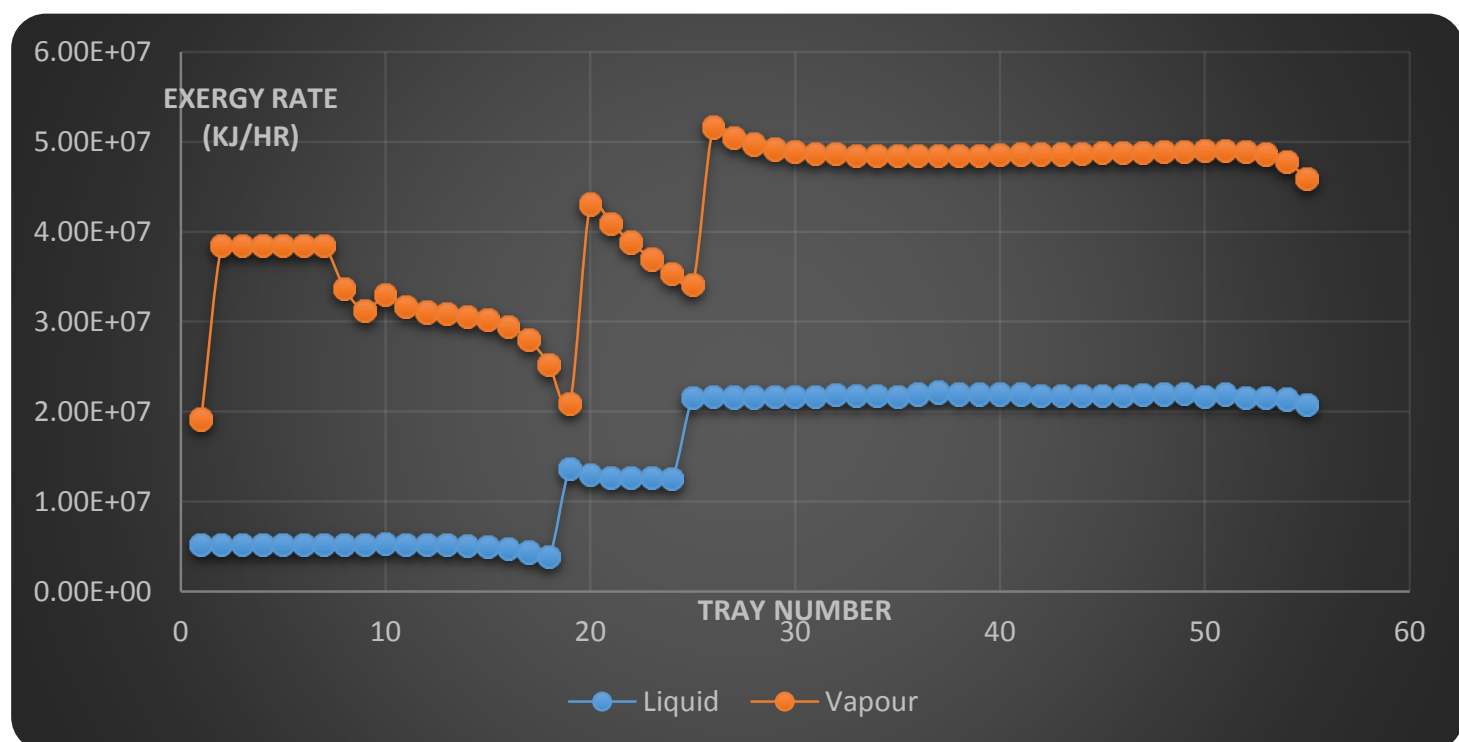

Fig. 5: Profile of Exergy Rate versus Tray Number the for Depropanizer of the Base Case Multiple Feed

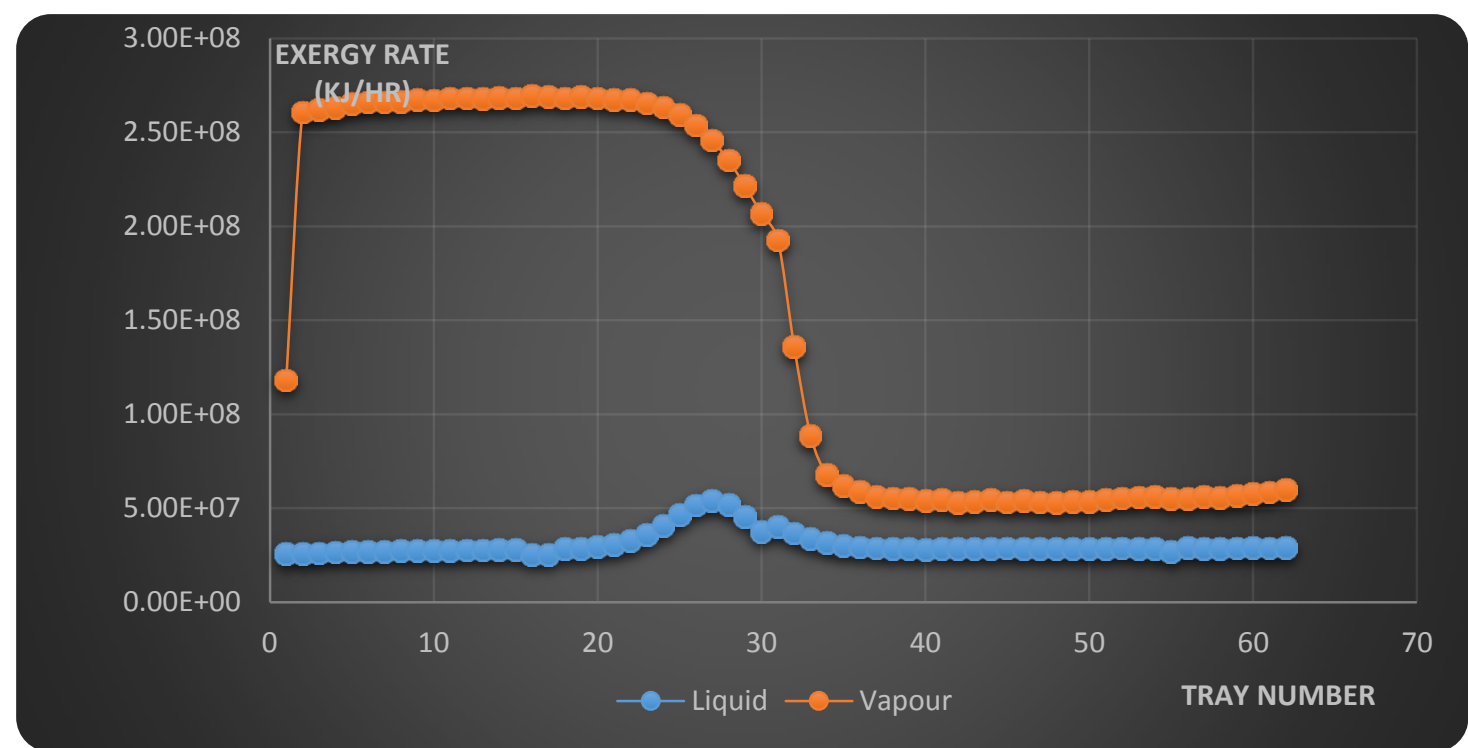

Fig. 6: Profile of Enthalpy Rate versus Tray Number the for Debutanizer of the Base Case Multiple Feed 


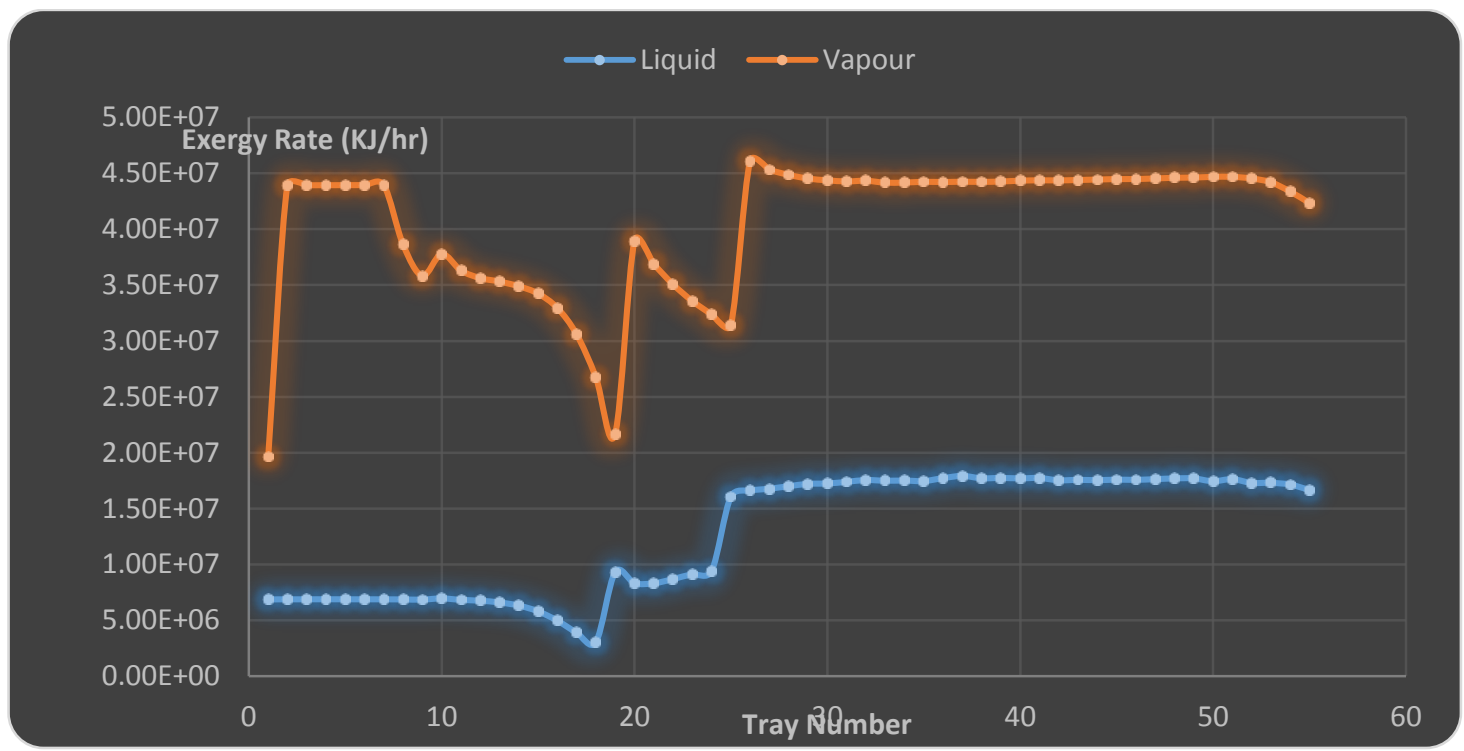

Fig. 7: Profile of Exergy Rate versus Tray Number for Depropanizer of Base Case, 30oc

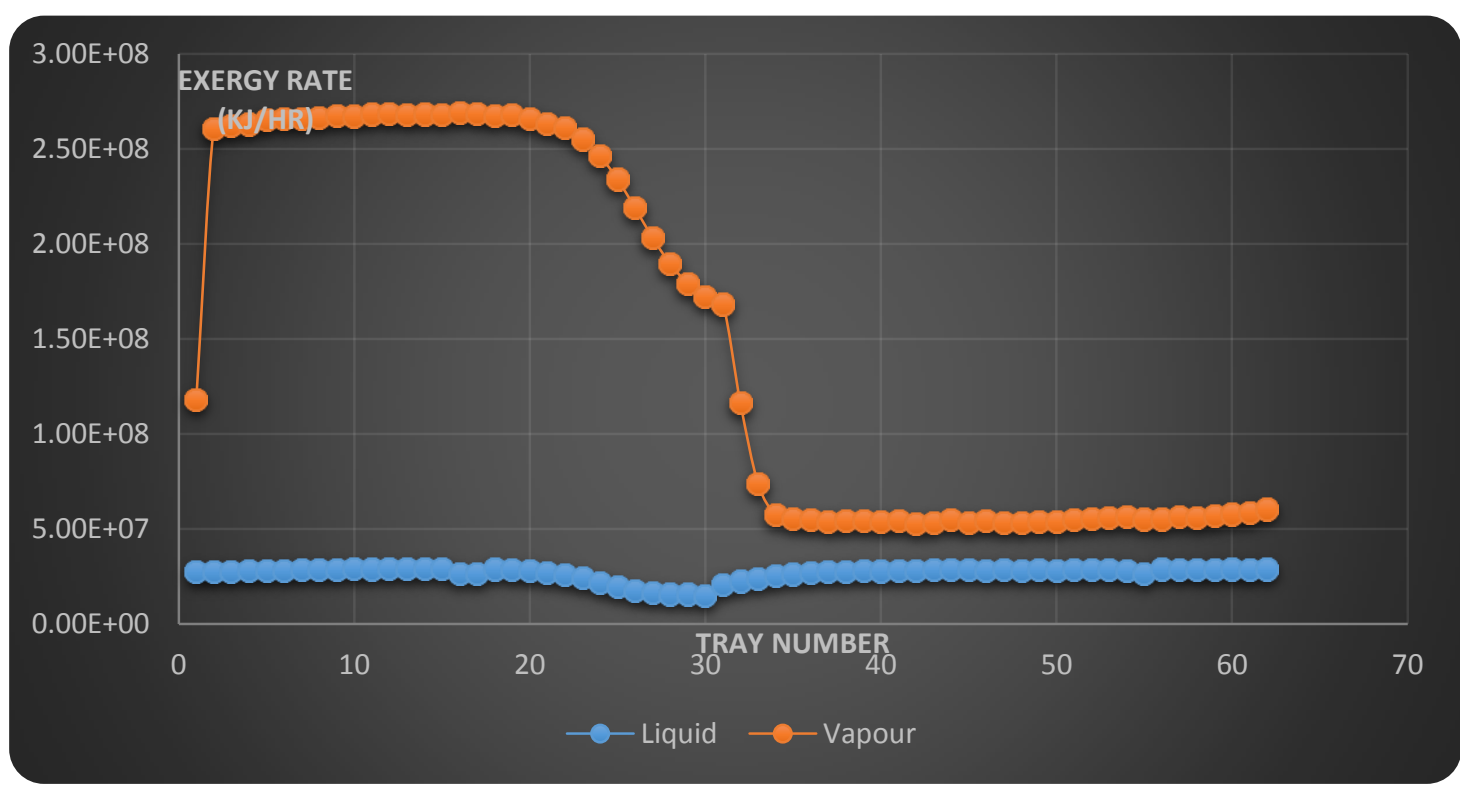

Fig. 8: Profile of Exergy Rate versus Tray Number for Debutanizer of Base Case, 30oc

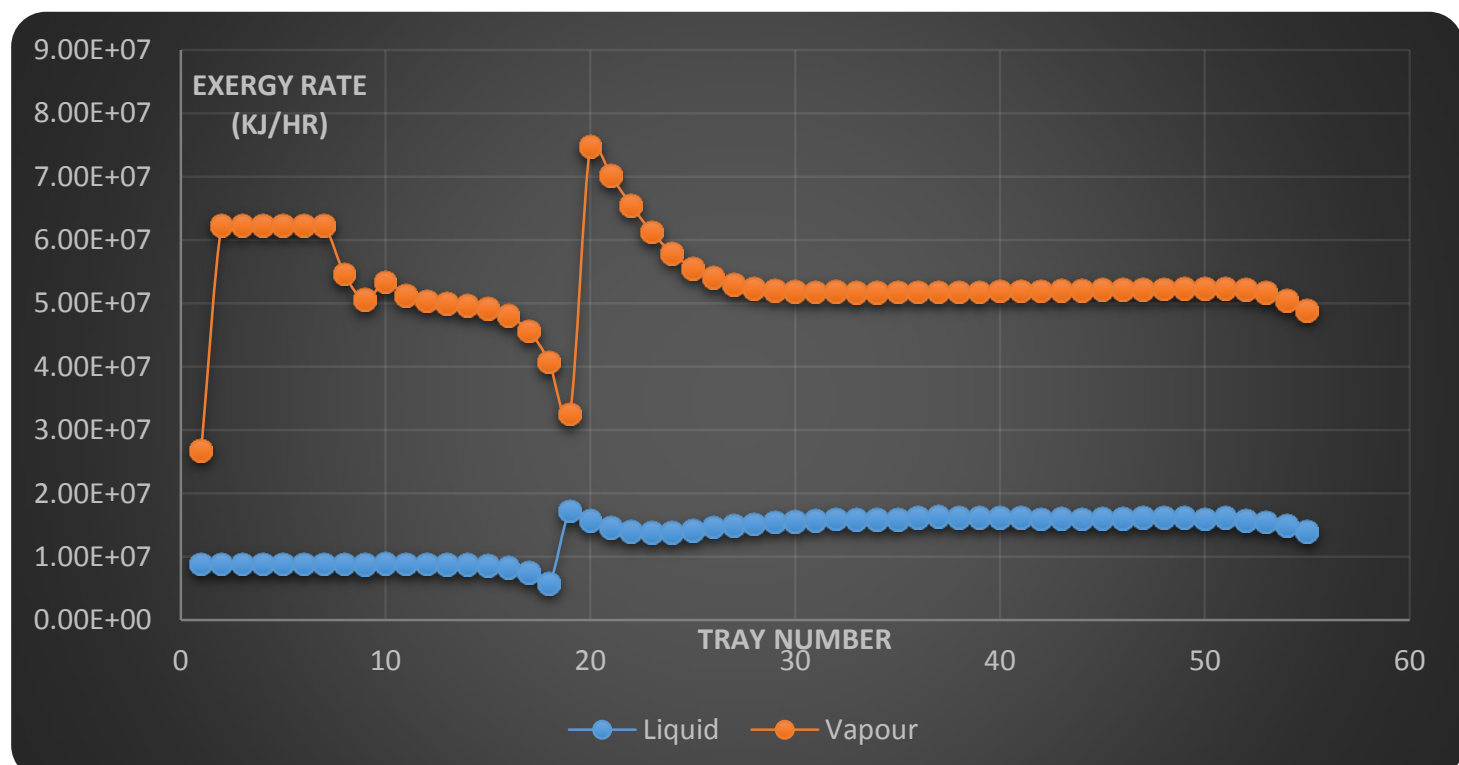

Fig. 9: Profile of Exergy Rate versus Tray Number for Depropanizer of Base Case, 80oc. 


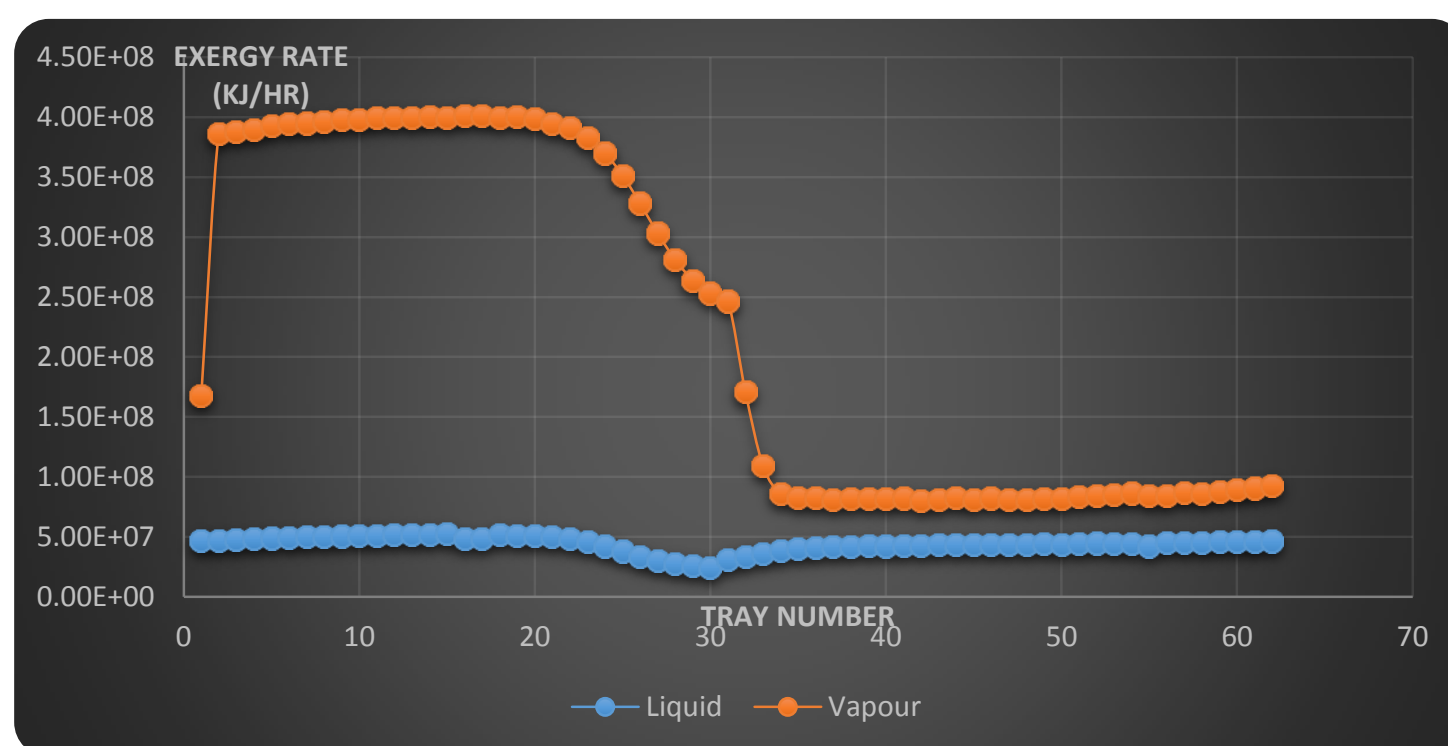

Fig. 10: Profile of Exergy Rate versus Tray Number for Depropanizer of Base Case, 80oc

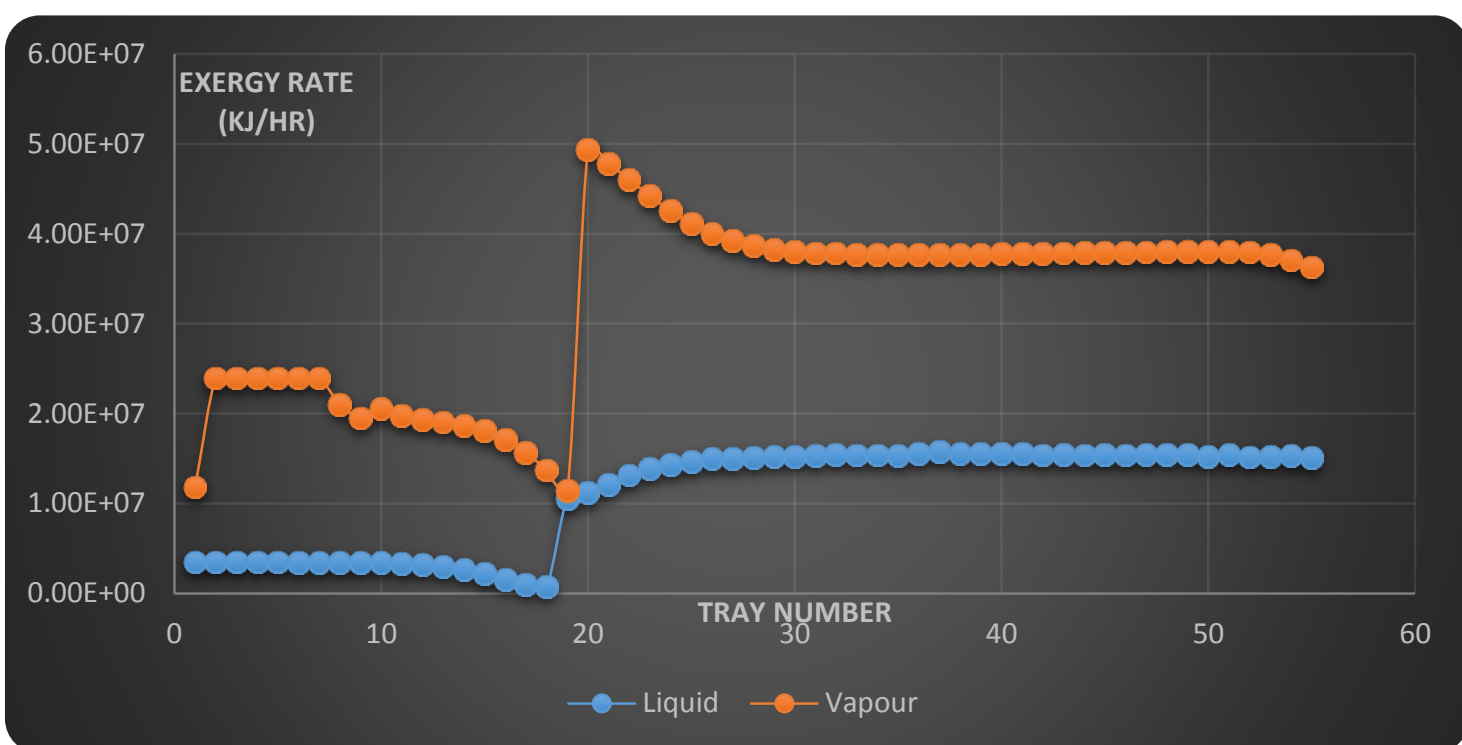

Fig. 11: Profile of Exergy Rate versus Tray Number for Depropanizer of Base Case, 30oc, Reflux Ratio 2

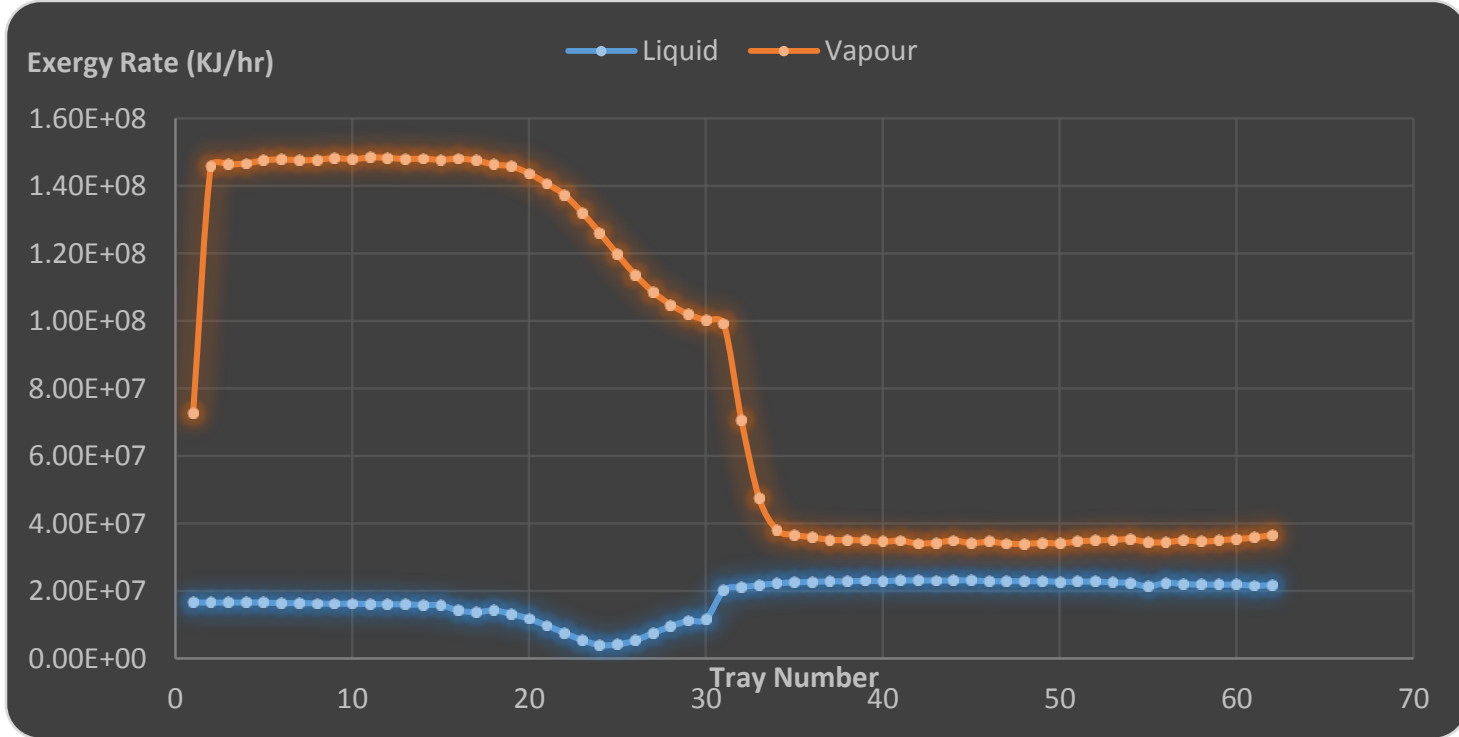

Fig. 12: Profile of Exergy Rate versus Tray Number for Debutanizer of Base Case, 30oc, Reflux Ratio 2 


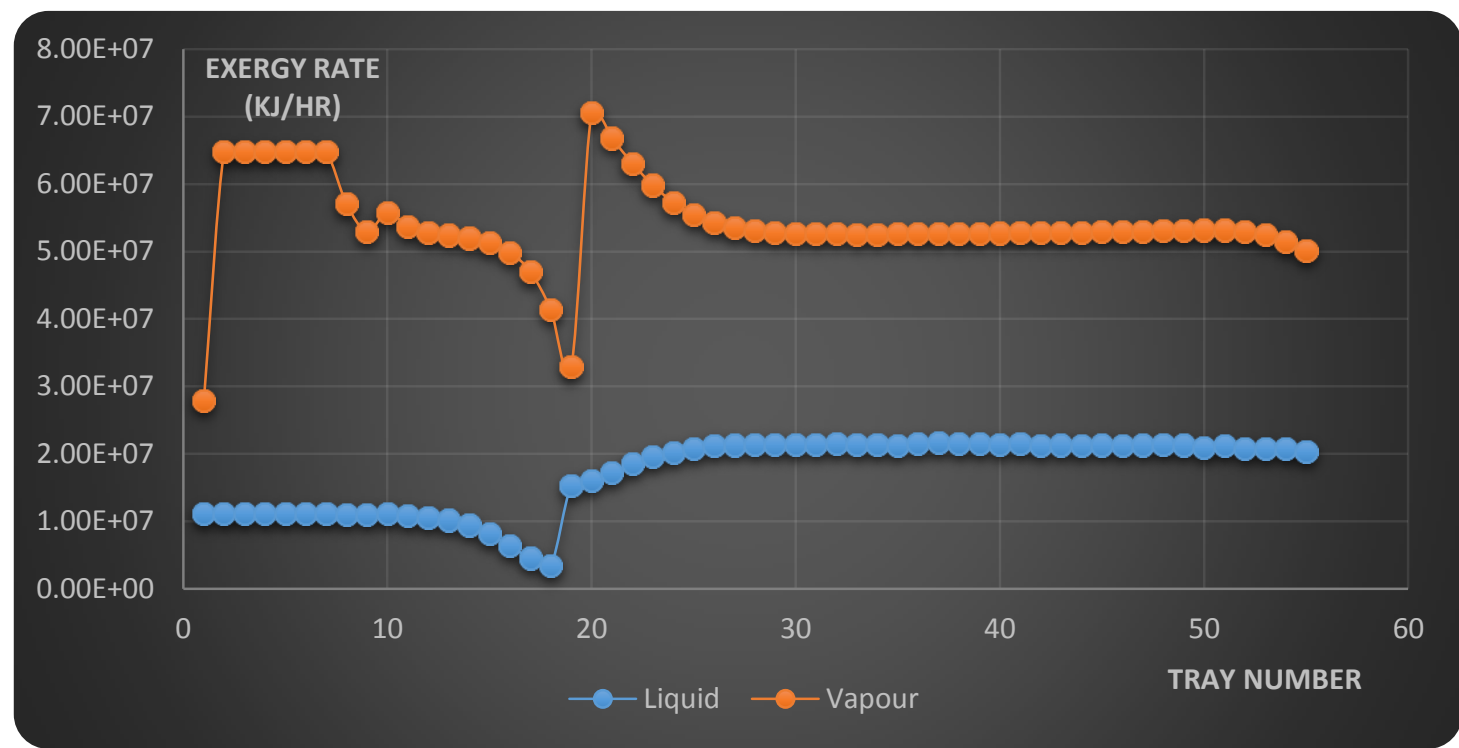

Fig. 13: Profile of Exergy Rate versus Tray Number for Depropanizer of Base Case, 30oc, Reflux Ratio 6

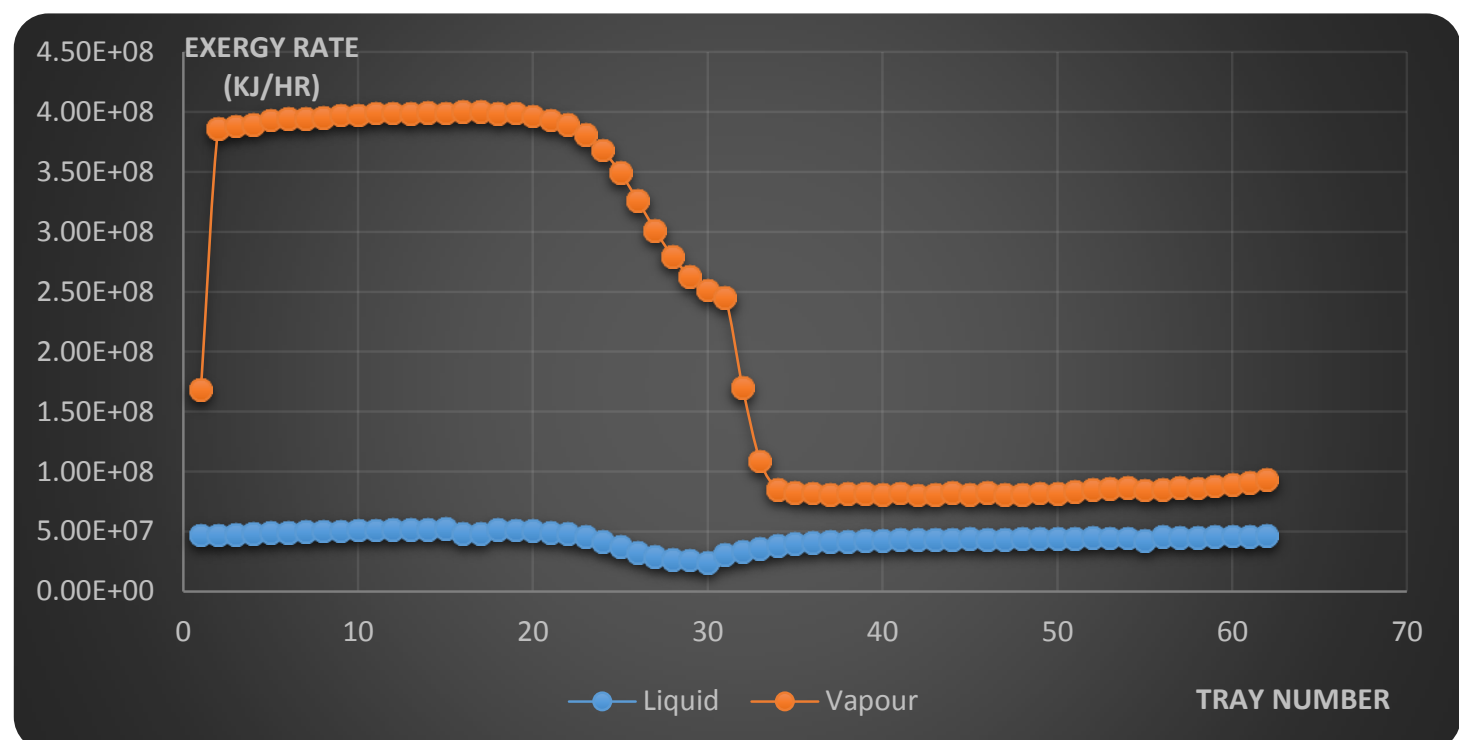

Fig. 14: Profile of Exergy Rate versus Tray Number for Depropanizer of Base Case, 30oc, Reflux Ratio 6

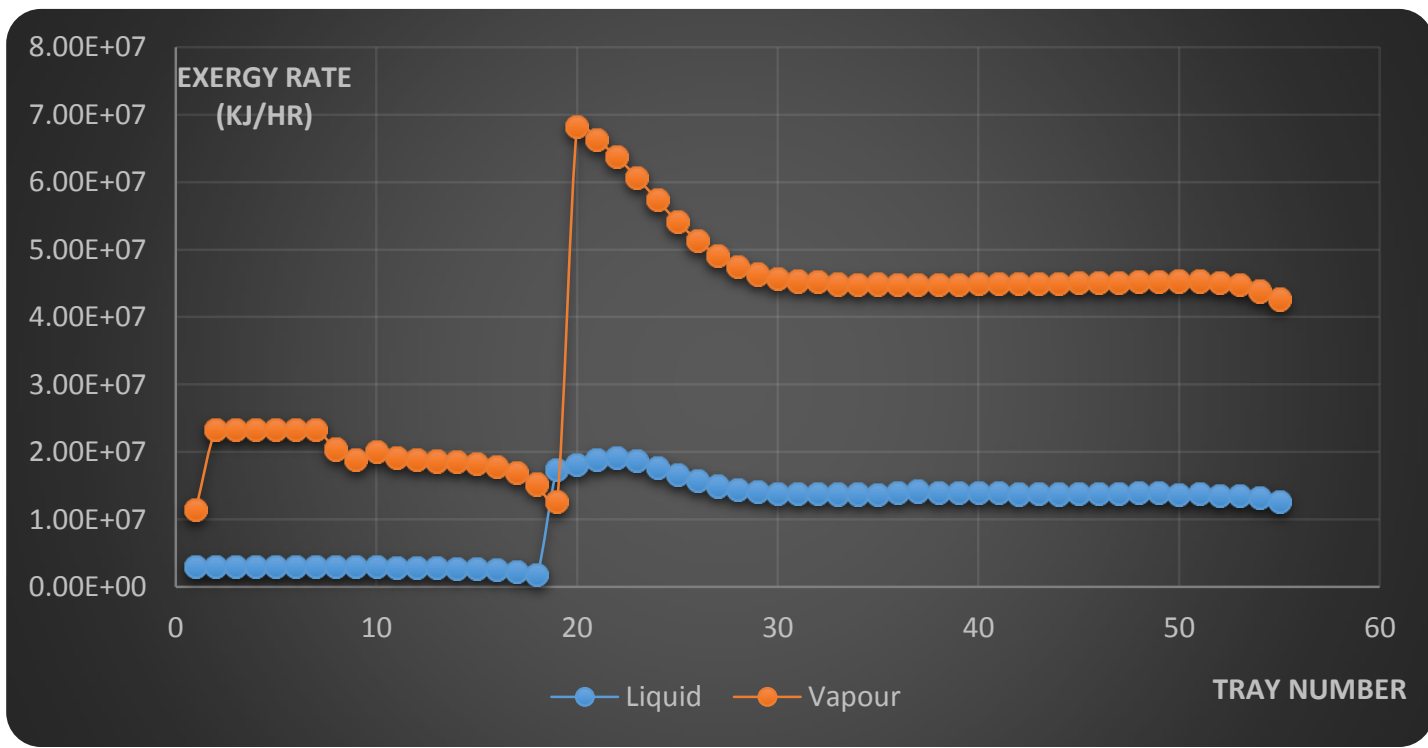

Fig. 15: Profile of Exergy Rate versus Tray Number for Depropanizer of Base Case, 80oc, Reflux Ratio 2 


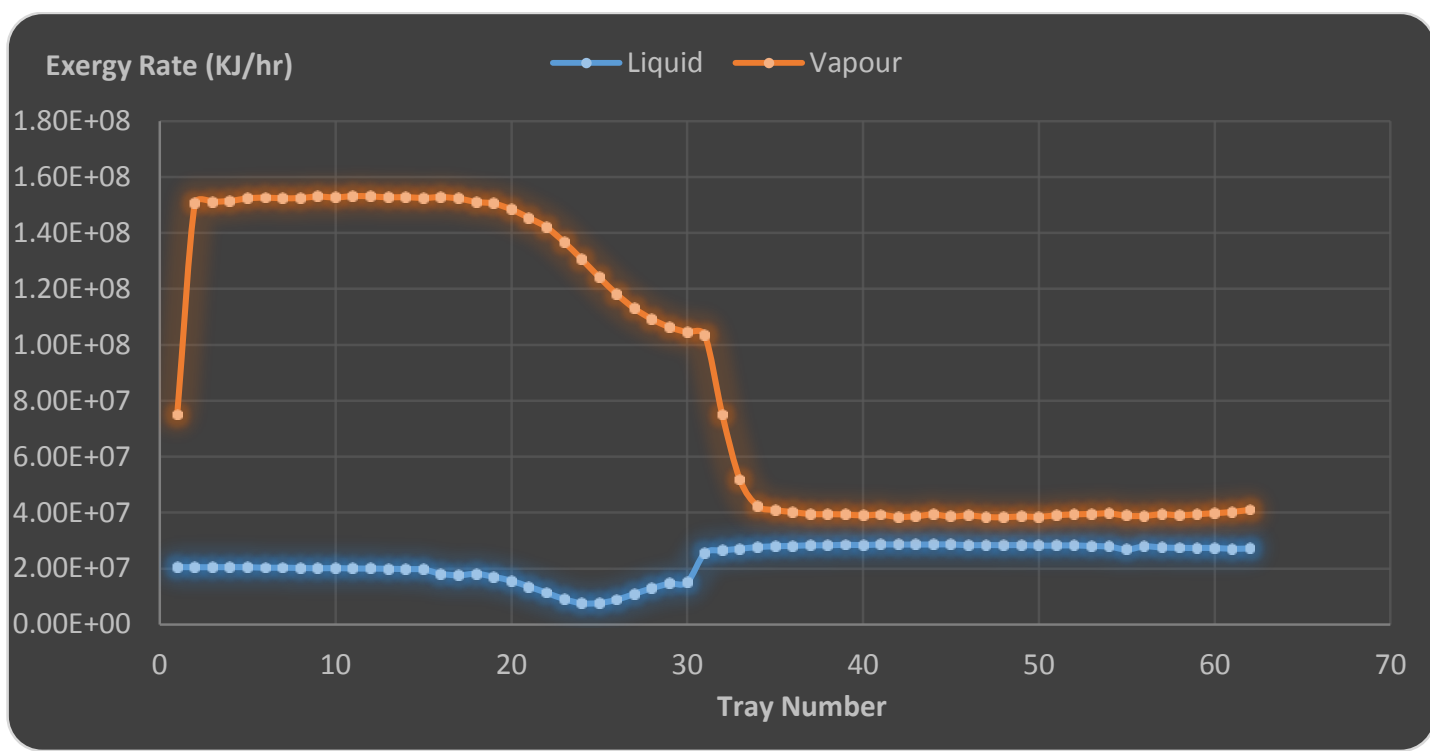

Fig. 16: Profile of Exergy Rate versus Tray Number for Debutanizer of Base Case, 80oc, Reflux Ratio 2.

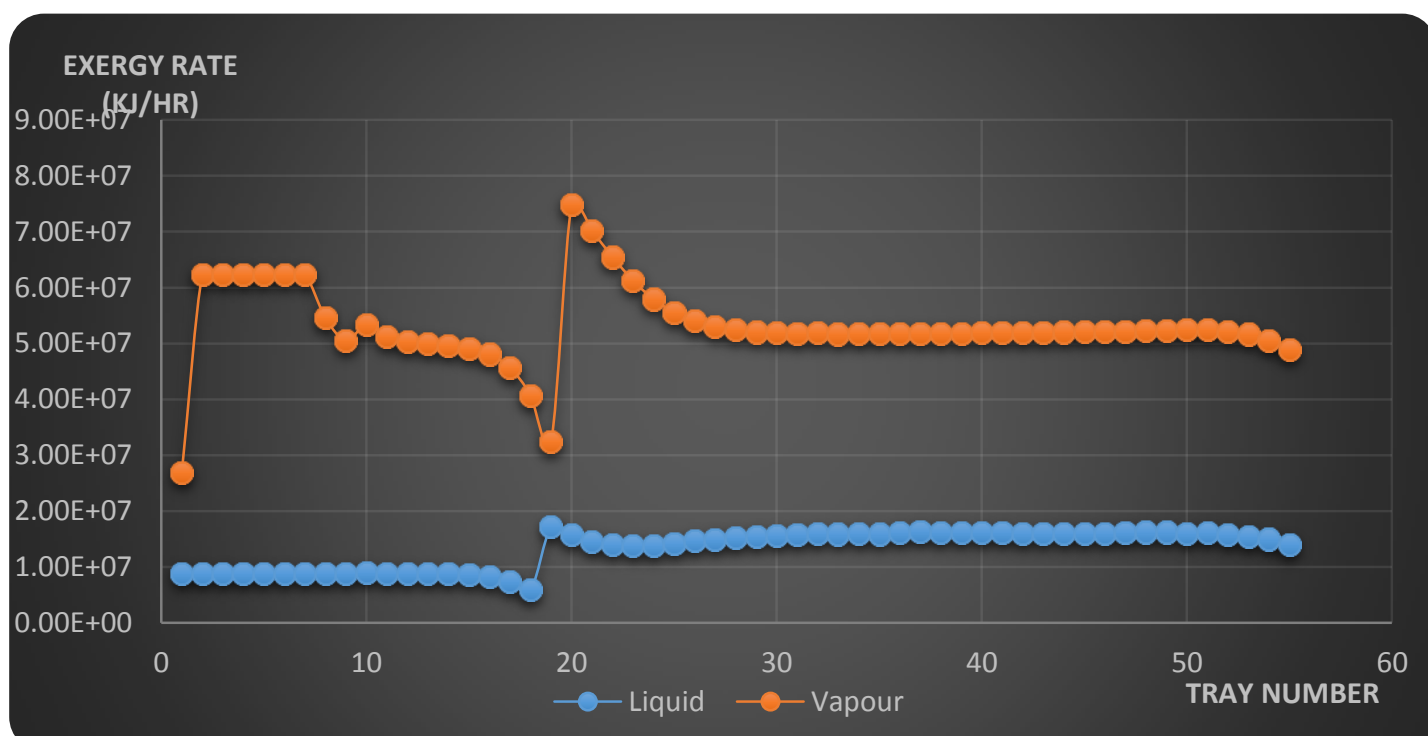

Fig. 17: Profile of Exergy Rate versus Tray Number for Depropanizer of Base Case, 80oc, Reflux Ratio 6

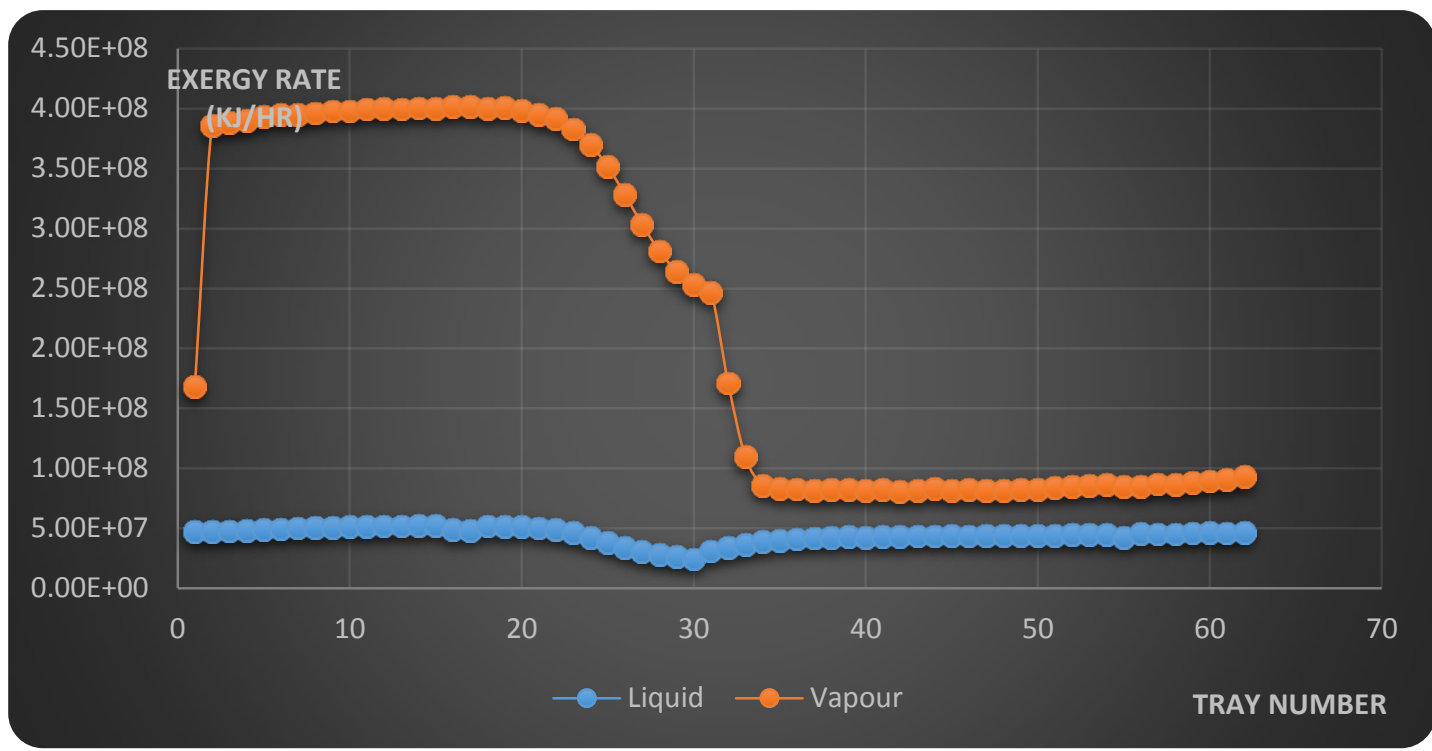

Fig. 18: Profile of Exergy Rate versus Tray Number for Debutanizer of Base Case, 80oc, Reflux Ratio 6 


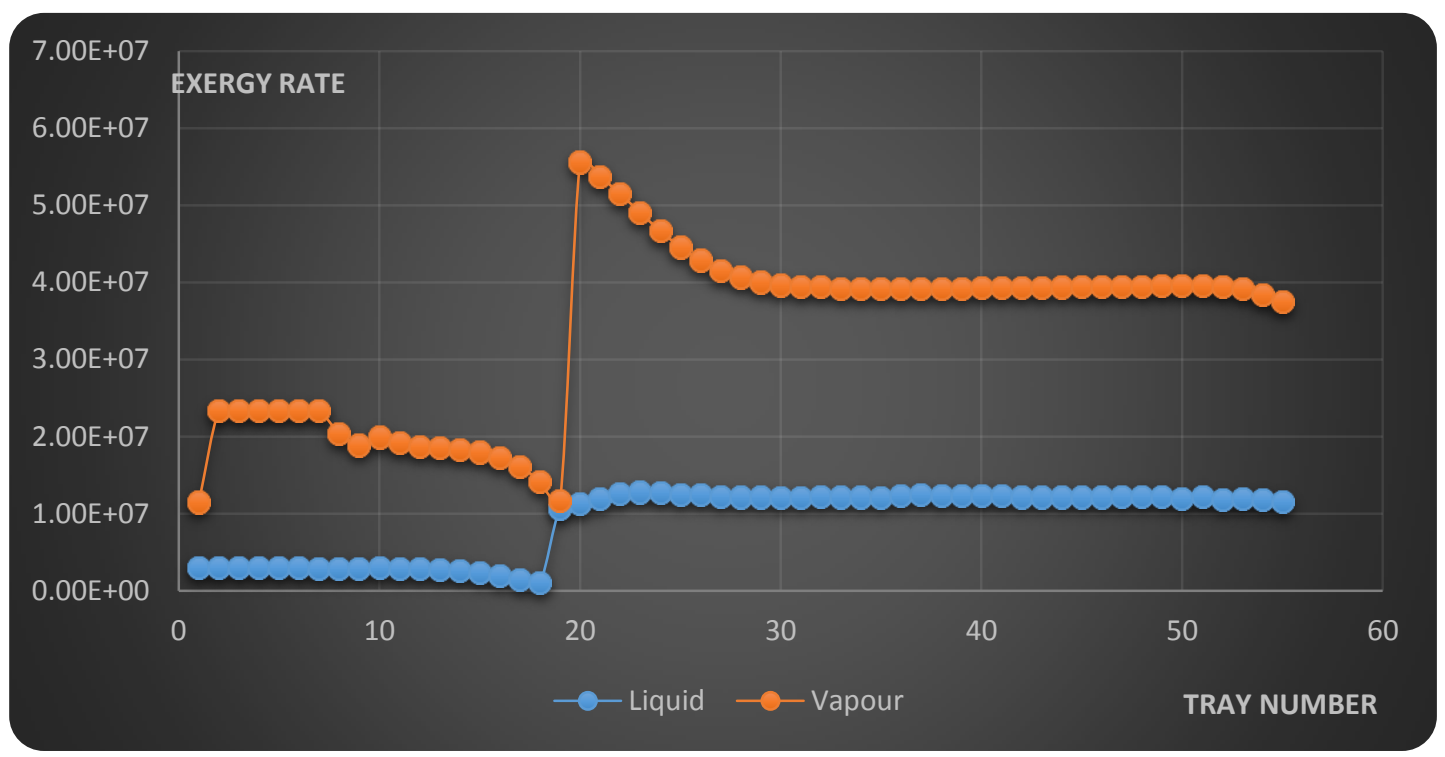

Fig. 19: Profile of Exergy Rate versus Tray Number for Depropanizer of Base Case, Reflux Ratio 2.

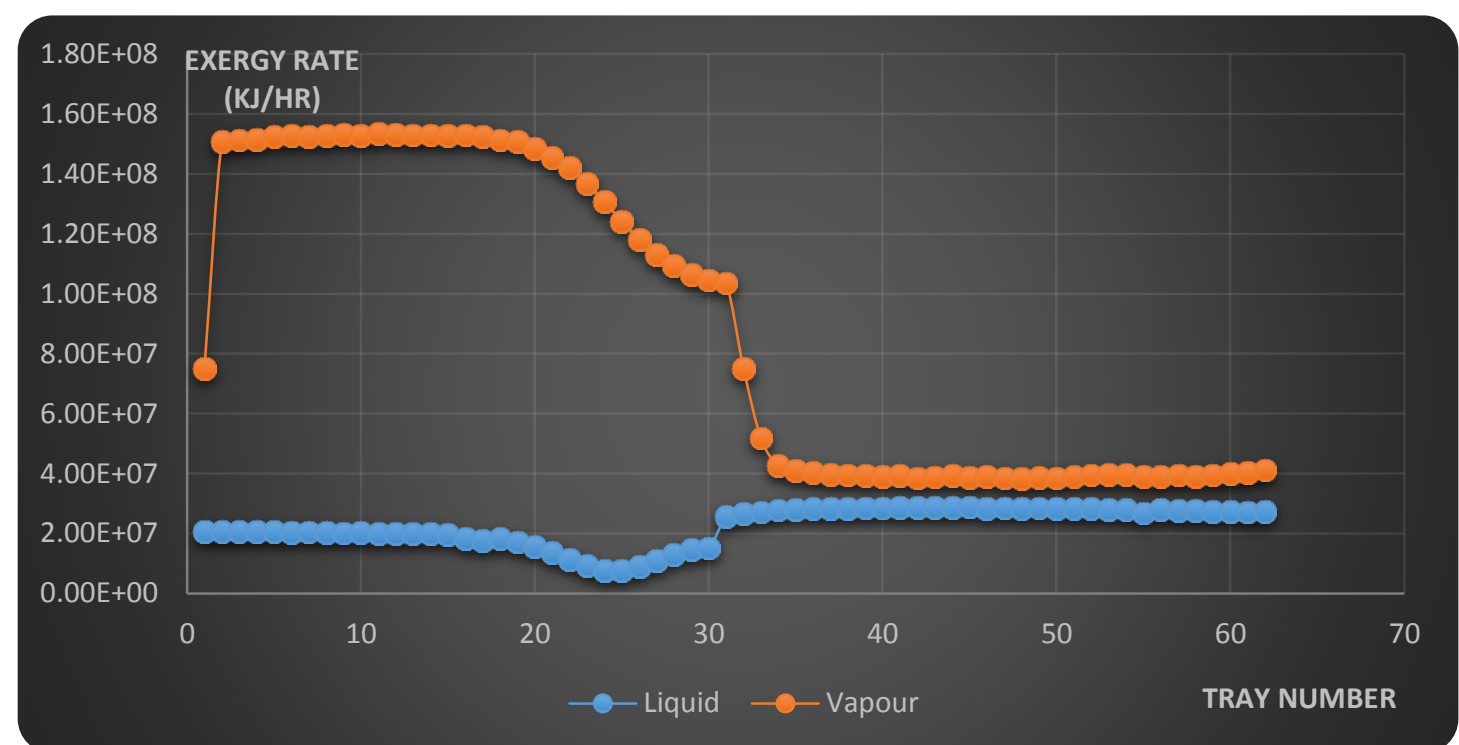

Fig. 20: Profile of Exergy Rate versus Tray Number for Debutanizer of Base Case Reflux Ratio 2

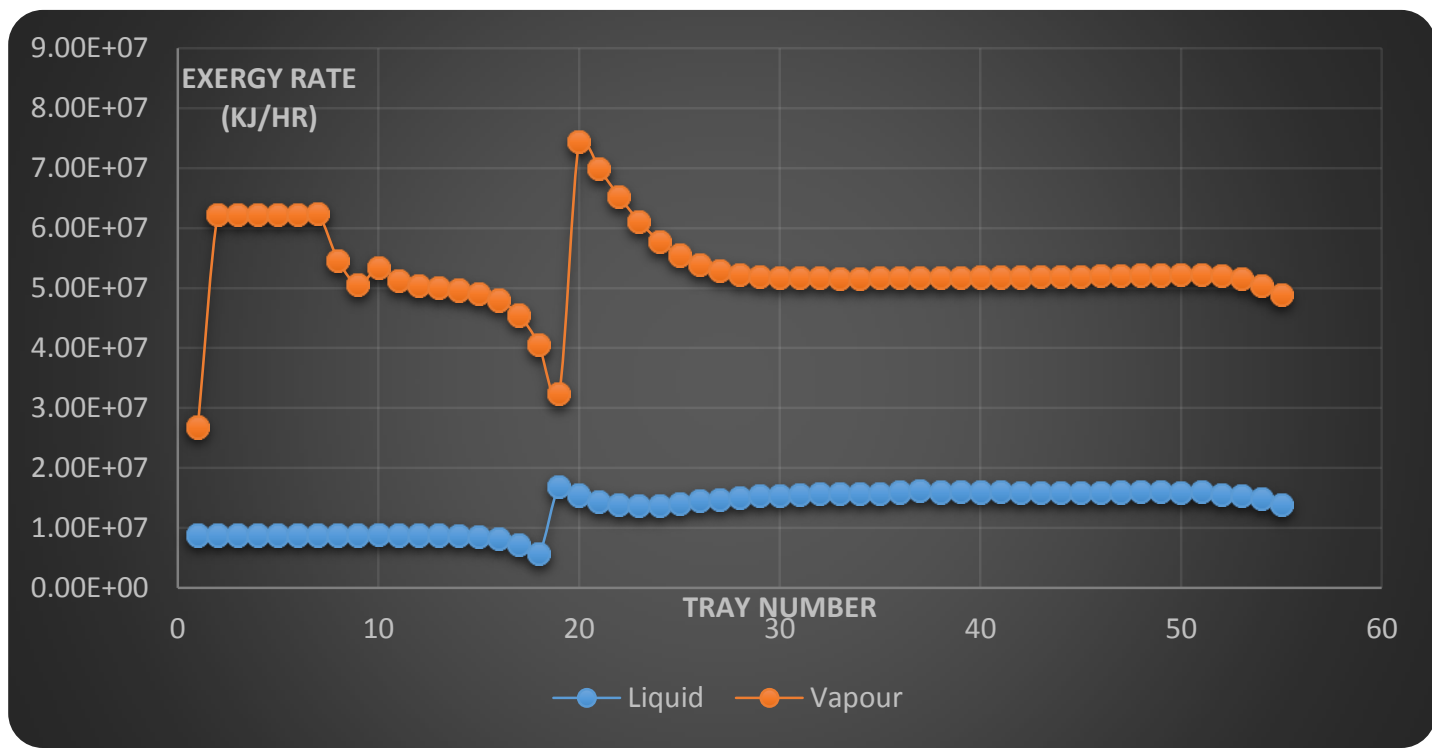

Fig. 21: Profile of Exergy Rate versus Tray Number for Depropanizer of Base Case, Reflux Ratio 6 


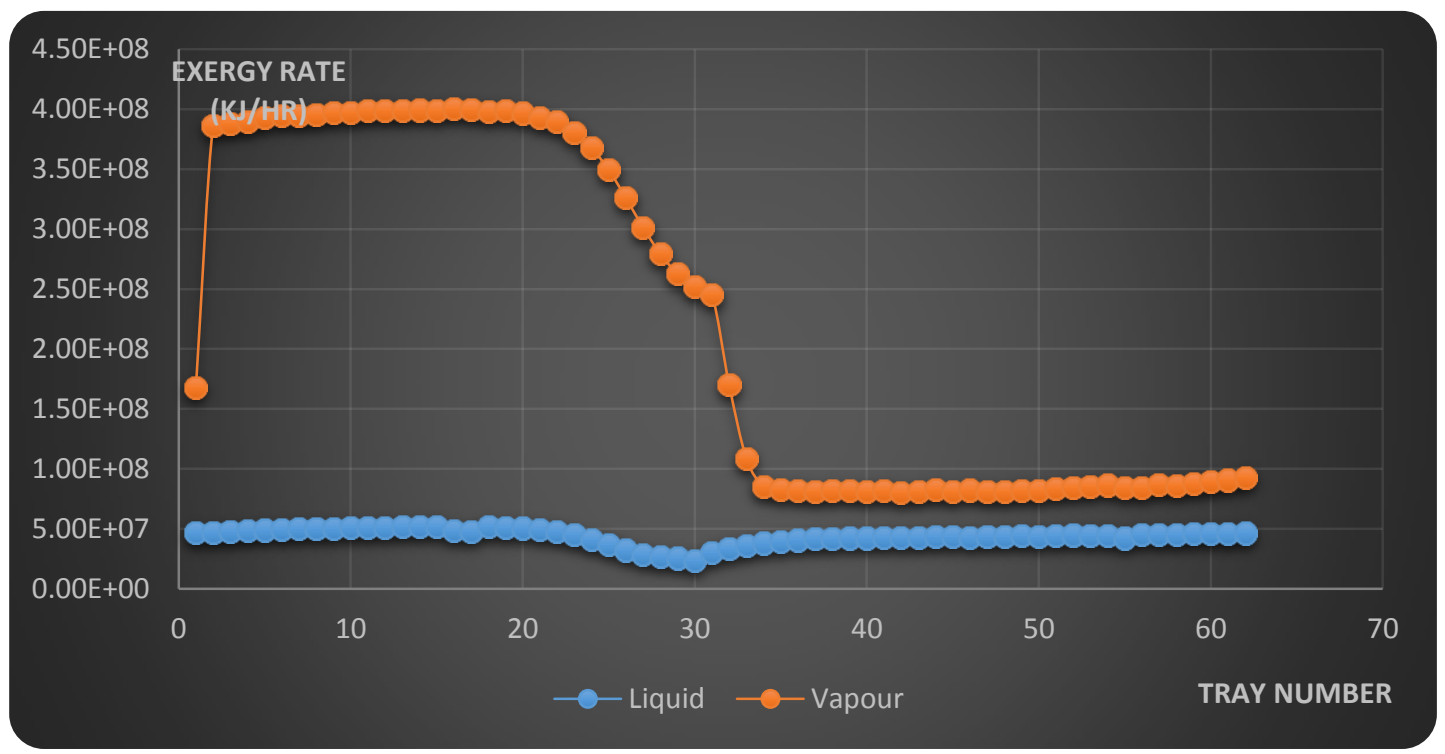

Fig. 22: Profile of Exergy Rate versus Tray Number for Depropanizer of Base Case, Reflux Ratio 6

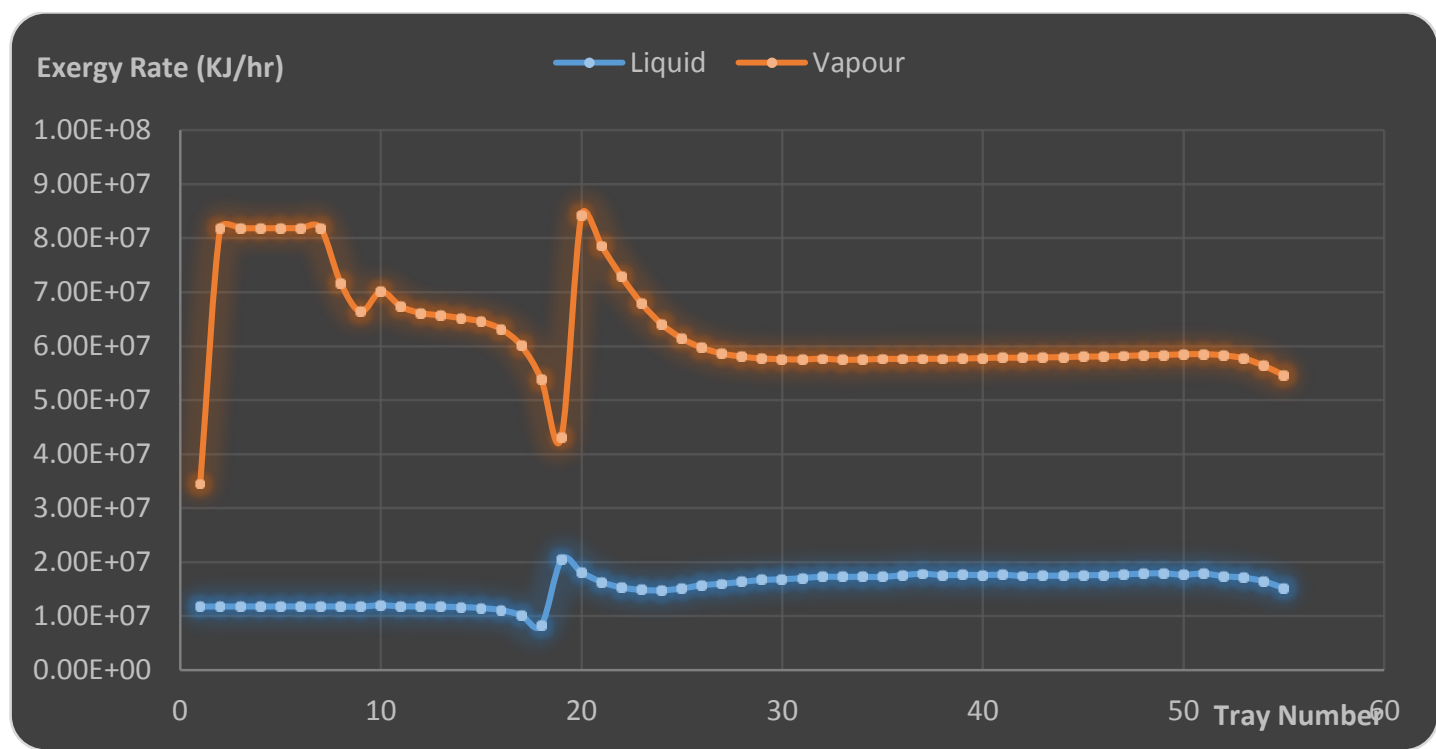

Fig. 23: Profile of Exergy Rate versus Tray Number for Depropanizer of Base 1200kpa Case

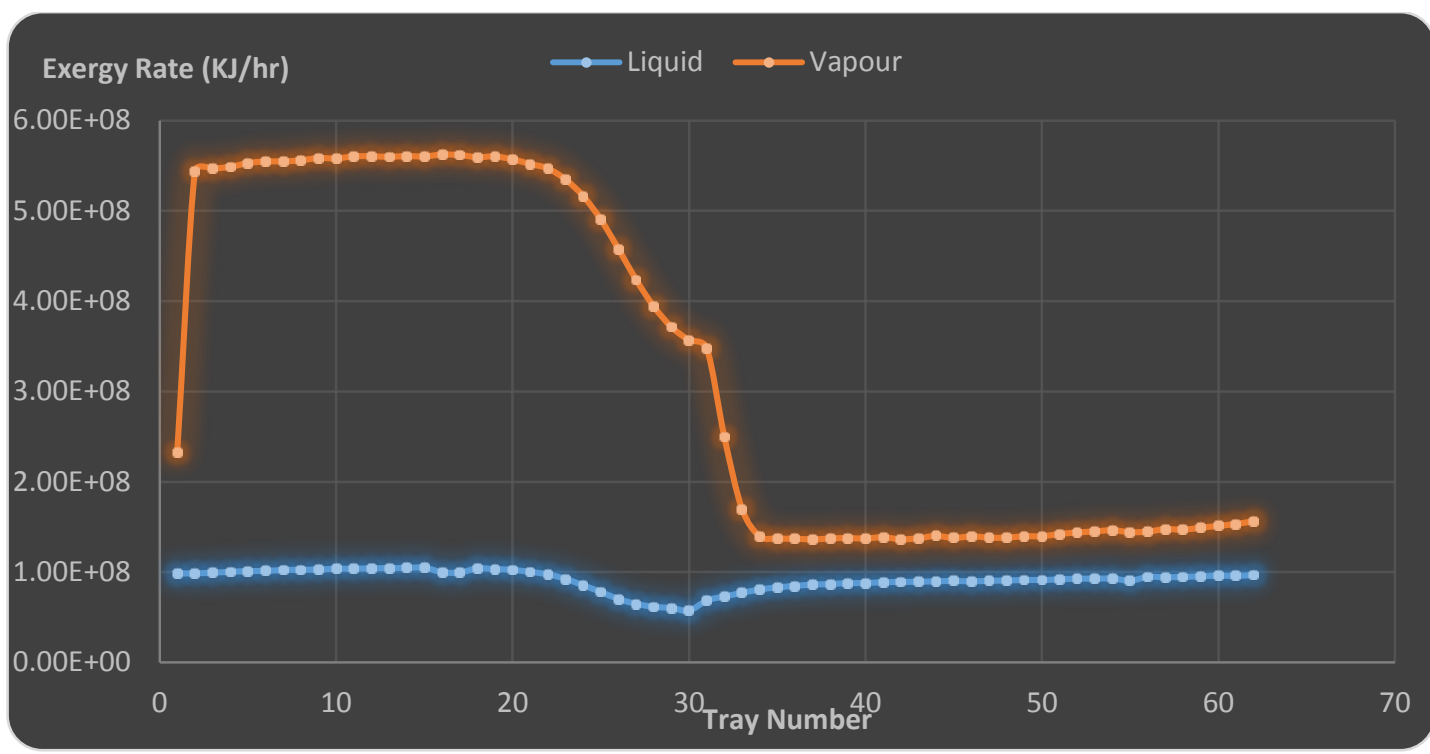

Fig. 24: Profile of Exergy Rate versus Tray Number for Debutanizer of Base 1200kpa Case 


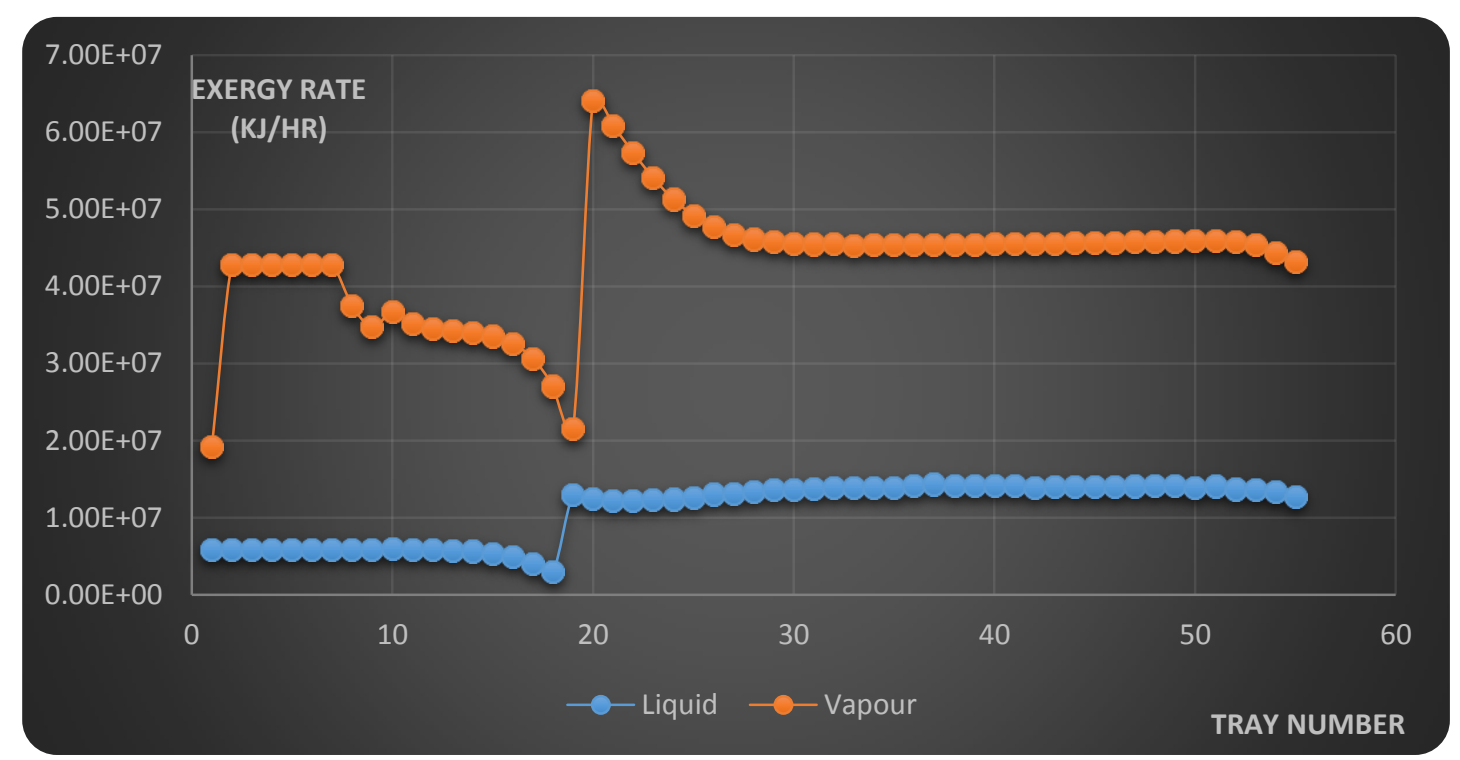

Fig. 25: Profile of Exergy Rate versus Tray Number for Depropanizer of Base 800kpa Case.

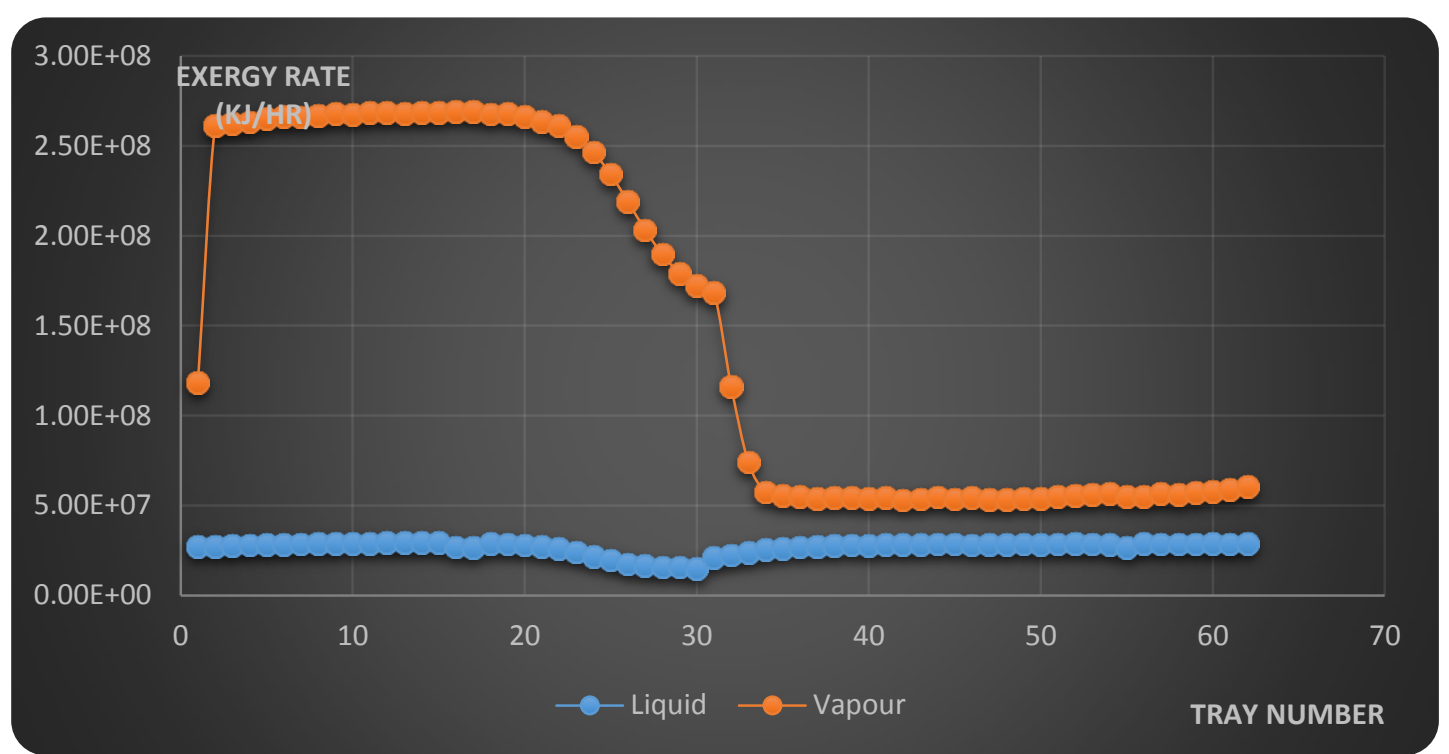

Fig. 26: Profile of Exergy Rate versus Tray Number for Debutanizer of Base 800kpa Case

\section{References}

[1] Alatiqi, I.M. and Luyben, W.L. Alternative distillation configurations for separating ternary mixtures with small concentration of intermediate in the feed, Ind Eng Chem Process Des Dev, 24, 1985, 500-506 http://dx.doi.org/10.1021/i200029a047.

[2] Al-Muslim H., and Dincer I. Thermodynamic analysis of crude oil distillation systems, International Journal of Energy Research, 29, 2005, 637 http://dx.doi.org/10.1002/er.1097.

[3] Blancarte-Palacios, J.L., Bautista-Valde's, M.N., Herna'ndez, S., Rico-Ramı'rez, V. and Jime'nez, A. Energy-efficient designs of thermally coupled distillation sequences for four-component mixtures, Ind Eng Chem Res, 21, 2003, 5157-5164 http://dx.doi.org/10.1021/ie030297k.

[4] Christiansen, A.C., Skogestad, S. and Lien, K. Complex distillation arrangements: extending the Petlyuk idea, Comput Chem Eng, 21, 1997, S237-S242. http://dx.doi.org/10.1016/S0098-1354(97)87508-4.

[5] Demirel, Y. Retrofit of distillation columns using thermodynamic analysis. Separation Sciences and Technology, $41,2006,791817$. http://dx.doi.org/10.1080/01496390600600047.

[6] Dhole V.R., and Linnhoff B. Distillation Column Targets, Computers and Chemical Engineering 17, 1993, 549-560. http://dx.doi.org/10.1016/0098-1354(93)80043-M.

[7] Engelien HK, Larsson T, and Skogestad S. Implementation of Optimal Operation for Heat IntegratedDistillation Columns, Trans Inst Chem Eng; 81, 2003, 277-81. http://dx.doi.org/10.1205/026387603762878755.

[8] Faria, S.H.B., and Zemp, R. J. Using exergy loss profiles and enthalpy-temperature profiles for the evaluation of thermodynamic efficiency in distillation columns, J. Thermal Engineering, Vol. 4, No. 4, 2005, 76 -82.

[9] Flores, O. A., Cardenas, C., Hernandez, S., and RicoRamyrez, V. Thermodynamic Analysis of Thermally Coupled Distillation Sequences, Ind. Eng. Chem. Res., 42, 2003, 5940. http://dx.doi.org/10.1021/ie034011n.

[10] Finn, A.J. Consider thermally coupled distillation, Chem Eng Prog, 10, 1993, 41-45.

[11] Fidkowski, Z. and Krolikowski, L. Energy requirements of nonconventional distillation systems, AIChE J, 36, 1990, 1275-1278 http://dx.doi.org/10.1002/aic.690360820.

[12] Glinos, K. and Malone, F. Optimality regions for complex column alternatives in distillation systems, Trans IChemE, Part A, Chem Eng Res Des., 66, 1998, 229-240. 
[13] Herna'ndez, S. and Jime'nez, A. Design of optimal thermally-coupled distillation systems using a dynamic model, Trans IChemE, Part A, Chem Eng Res Des., 74, 1996, 357-362.

[14] Herna'ndez, S. and Jime'nez, A. Design of energy-efficient Petlyuk systems, Comput Chem Eng, 23, 1999 a, 1005-1010. http://dx.doi.org/10.1016/S0098-1354(99)00257-4.

[15] Hsuan, C., and Jr-Wie, L., A new exergy method for process analysis and optimization, Chemical Engineering Science., 60, 2005, 2771 http://dx.doi.org/10.1016/j.ces.2004.12.029.

[16] King, C.J., Separation Processes (McGraw-Hill, New York, 2nd edition, 1980).

[17] Le Goff, P., and Hornut, J.M. Exergy analysis and exergo-economic optimization of industrial process (Janvier-Fevrier, 1998).

[18] Linnhoff, B. and Alanis, F. J. Integration of a New Process into an Existing Site: A Case Study in the Application of Pinch Technology," ASME Journal of Engineering for Gas Turbines and Power, Vol. 113, 1991, 159-169. http://dx.doi.org/10.1115/1.2906537.

[19] Le Goff, P., Cachot, T. and Rivero, R. Exergy analysis of distillation process. Chemical Engineering and Technology, Vol. 19, 1996, 478 485 http://dx.doi.org/10.1002/ceat.270190603.

[20] Maia M. L. O., Zemp R.J. Thermodynamic analysis of multicomponent distillation columns: identifying optimal feed conditions, Brazilian Journal of Chemical Engineering, vol 17, 2000, 751-759. http://dx.doi.org/10.1590/S0104-66322000000400038.

[21] Olujic, Z., Fakhri, F., De Rijke, A., De Graauw J., and Jansens, P.J. Internal heat integration - the key to an energy-conserving distillation column, Journal of Chemical Technology and Biotechnology. 78, 2003, 241 http://dx.doi.org/10.1002/jctb.761.

[22] Rivero, R., 1993, "L'Analyse d'Exergie: Application à la Distillation Diabatique et aux Pompes à Chaleur à Absorption", PhD thesis, Institut National Polytechnique de Lorraine, Nancy, France.

[23] Rivero, R., and Koeijer, G. Entropy production and exergy loss in experimental distillation columns, Chemical Engineering Science, 58, 2003, 1587. http://dx.doi.org/10.1016/S0009-2509(02)00627-9.

[24] Rong, B., Kraslawski, A., and Nystrom, L. The synthesis $\mathrm{f}$ thermally coupled distillation flowsheets for separations of five component mixture, Computers Chem. Engng., 24, 2000, 247 - 252. http://dx.doi.org/10.1016/S0098-1354(00)00466-X.

[25] Ruchira, T., and Masaru, I. Graphical exergy analysis of processes in distillation column by energy utilization diagrams. AIChE Journal, Vol. 42, No 6, 1996, 1633-1641. http://dx.doi.org/10.1002/aic.690420615.

[26] Tedder, D.W. and Rudd, D.F. Parametric studies in industrial distillation: Part I. Design comparisons. AIChE J, 24: 1978, 303-315. http://dx.doi.org/10.1002/aic.690240220.

[27] Santanu, B. Effect of feed on optimal thermodynamic performance of a distillation column. Chemical Engineerin Journal, Vol. 88. 2002, 175186. http://dx.doi.org/10.1016/S1385-8947(01)00303-5.

[28] Taprap, R., and Ishida, M. Graphic exergy analysis of processes in distillation column by energy-utilization diagrams, AIChE Journal, Vol. 42, No. 6, 1996, 1633. http://dx.doi.org/10.1002/aic.690420615.

[29] Zemp R.J., de Faria S.H.B, Maia M.L.O. Driving force distribution and exergy loss in the thermodynamic analysis of distillation columns, Computers and Chemical Engineering, Vol 21S, 1997, S52 http://dx.doi.org/10.1016/S0098-1354(97)87555-2. 